\title{
Design Evolution and AHP-based Historiography of Lifting Reentry Vehicle Space Programs
}

\author{
Loveneesh Rana* and Bernd Chudoba ${ }^{\dagger}$ \\ University of Texas at Arlington, TX-76019-0018
}

\begin{abstract}
The term "Historiography" is defined as the writing of history based on the critical examination of sources. In the context of space access systems, a considerable body of literature has been published addressing the history of lifting-reentry vehicle(LRV) research. Many technical papers and books have surveyed legacy research case studies, technology development projects and vehicle development programs to document the evolution of hypersonic vehicle design knowledge gained from the early 1950s onwards. However, these accounts tend to be subjective and qualitative in their discussion of the significance and level of progress made. Even though the information addressed in these surveys is considered crucial, it may lack qualitative or quantitative organization for consistently measuring the contribution of an individual program.

The goal of this study is to provide an anatomy aimed at addressing and quantifying the contribution of legacy programs towards the evolution of the hypersonic knowledge base. This paper applies quantified analysis to legacy lifting-reentry vehicle programs, aimed at comprehensively capturing the evolution of LRV hypersonic knowledge base. Beginning with an overview of literature surveys focusing on hypersonic research programs, a comprehensive list of LRV programs, starting from the 1933 Silvervogel to the 2015 Dream Chaser, is assembled. These case-studies are assessed on the basis of contribution made towards major hypersonic disciplines. The Analytical Hierarchy Process (AHP) is used to develop an analytical model, to quantify and measure the strength and weakness of primary disciplines for every case-study. Sixty national and international case-studies are evaluated based on one system-level and five discipline-based criteria addressing aerothermodynamics, structure \& materials, propulsion, thermal, and sub-system contributions. The AHP model allows a comparative assessment among the case-studies based on quantitative results, which identify a case-studys value and contribution for the growth of the primary disciplines, and the evolution of the overall hypersonic knowledge base. This analysis is further supported by an overview of the case-studies accessed, providing a brief description of LRV research history. An evolutionary pattern among the case-studies is recognized, demonstrating common aspects and influences of major programs throughout history.
\end{abstract}

\section{Introduction}

If I have seen further it is by standing on the shoulders of giants.

- Isaac Newton

It is best said by Sir Isaac Newton in the above quote that the fastest way to learn is by utilizing the knowledge gained by the previous generations. Contrary to this philosophy, the space industry has demonstrated a trend where knowledge is kept classified pertaining to the sensitive nature of the information related to national defense and company proprietary issues. This practice has resulted in a knowledgevoid, where the new generation of researchers are at risk of not being aware of the rich legacy of previous generations, which either tends to reside in the archives of the historical space programs or they have been lost over the years.

The first generation of Space access systems (SAS) were rocket launched ballistic reentry capsule designs, employed in the Mercury, Gemini and Apollo programs in the US and the Soyuz program in the USSR. In contrast to this simple very low hypersonic lift-to-drag ratio ballistic reentry capsule type design, a select group

*PhD Candidate (loveneesh.rana@mavs.uta.edu), ASE Laboratory, UT Arlington, AIAA Member.

${ }^{\dagger}$ Associate Professor (chudoba@uta.edu), Director ASE Laboratory, UT Arlington, AIAA Member 
of rocket scientists established the physical and operational advantages of utilizing aerodynamic lifting to enable the horizontal landing spaceplane-type concept. Snger \& Bredt, ${ }^{1}$ Tsien, Dornberger, Ehricke, ${ }^{2}$ Eggers, Allen \& Neice ${ }^{3}$ published the fundamental assessments addressing hypersonic lifting reentry vehicle(LRV) performance overall, demonstrating the conceptual feasibility. Following these seminal studies, space organizations around the world have initiated numerous programs to develop a SAS employing lifting reentry. The 1957 USAF X-20 program ${ }^{4}$ represents the first industry scale effort employing the LRV approach. The following decades have seen numerous multi-billion dollar programs fail to develop an operational vehicle, with only a few exceptions.

In spite of failure, these legacy programs contribute immensely towards understanding the hypersonic environment, the development of disciplinary analysis and design methods, and the evolution of new technology and industry capability. The body of lessons learned and technologies developed through these programs contribute directly to the next generation of vehicles, and is therefore of particular interest to the aerospace industry. This trend of natural progression is observed in multiple case-studies like X-20, X-34, X-38, HERMES etc., and is discussed in further detail in sections IV and V. In particular, the data collected during actual flight testing is supporting the development of predictive models for disciplinary and multi-disciplinary analysis and design throughout the aerospace development community. This aspect is highlighted in a 1968 experimental test vehicle, the Reentry-F test-data which is still used today to validate and refine new aerodynamics predictive models. ${ }^{5}$ Therefore, these legacy programs have to be considered as an essential body of knowledge, of direct relevance to present but in particular future generations of space systems.

The present study introduces a prototype approach of capturing certain knowledge gained during historical LRV programs. The study begins with a review of the major literature sources that document historical LRV programs. Following this review, a total of sixty national and international LRV programs are identified, starting from Eugen Sänger's 1933 Silvervogel to the currently active Sierra Nevada Corporation's Dream Chaser vehicle. These programs are used as case studies to develop an analytical model quantitatively assessing its contribution towards the primary hypersonic design disciplines. The AHP method is used to develop a numerical framework through which every case-study is assigned a final score indicating the holistic contribution of selected LRV programs towards (a) the overall hypersonic knowledge body, and (b) its contribution towards individual analysis disciplines. Following the AHP analyses of the case-studies, a brief overview is provided to assess and verify the numerical representation of the qualitative aspects captured by the model.

The primary goal is to develop a comparative framework to assess, identify and compare the disciplinary contribution and overall importance of selected LRV case-studies. A secondary goal is to apply this framework to historical LRV programs and trace the evolution of hypersonic knowledge through the selected case-studies. This study enables the reader to recognize enabling bodies of hypesonic LRV knowledge.

\section{Literature Review}

The advantages of using lifting reentry over ballistic reentry were established during the early 1950s by researchers like Eggers, Allen and Neice. ${ }^{3}$ Since then, a vast amount of research and development has been dedicated towards understanding the design and operational requirements of LRVs. However, even after more than six decades of spaceflight, only three spaceplane programs have been able to demonstrate hardware flight status, namely the: US Space Shuttle, USSR Buran and X-37. The history of lifting hypersonic vehicle development is filled with more failures than successes. Erbland addresses this notion with notables examples:

"History has shown hypersonic system development programs and flight demonstration programs to be very dynamic and somewhat unstable. Most programs proposed over the past 20 years have been terminated prior to reaching flight, for example; Hermes, HOTOL, Sänger, the National AeroSpace Plane (NASP) and several recent NASA X-vehicle programs including the $X$-33, $X$-34, $X$-38 and $X-43 B / C . . " 6$

It must be recognized here, that although most of these projects did not achieve hardware flight status, valuable knowledge was gained from the cancelled programs. The contributions of these programs are also recognized by several reputed authors as evident in the following excerpts:

Hirschel in reference [7] on the historical perspective of hypersonic programs: "Nevertheless, much 
insight and an appreciable technology base has been created, and several experimental vehicles have flown and contributed to this."

Hallion in reference [8]: "A review of some highlights from this history indicates much was accomplished relatively quickly, but also that, over time, advocates have encountered near-continuous frustration as they have attempted to go beyond some of these earlier experimental and study efforts towards operational military and civilian systems of eminent practicality."

Springer in reference [9]: "Over the last 50 years there have been hundreds if not thousands of separate design studies of various rockets and launch vehicles both expendable and reusable...These extensive studies from the 1960s and early 1970s form a significant body of work that is applicable to current and future vehicle configurations."

Space access is not an easy endeavor. Above cited quotes reaffirm that if we are to progress as a space fairing civilization, failure must be acknowledged and accepted. The lessons learned from the legacy programs must be studied and utilized while developing the next generation of SAS. This has been the motivation for a large body of literature, where authors have documented historical projects and programs over a very broad spectrum of vehicles. The following discussion provides a review of such literature sources and attempts to identify their shortcomings, to propose a new method of assessing the information residing in these valuable historical surveys.

\section{A. Hypersonic Historiography: Current State of Literature}

Definition of historiography ${ }^{10}$

i a : the writing of history; especially : the writing of history based on the critical examination of sources, the selection of particulars from the authentic materials, and the synthesis of particulars into a narrative that will stand the test of critical methods

$\mathrm{b}$ : the principles, theory, and history of historical writing

ii : the product of historical writing : a body of historical literature

The history of hypersonic research is filled with case-studies involving experimental projects and vehicle development programs, which have been documented extensively. The processes applied and data generated from these case-studies were originally documented in the technical reports authored by involved researchers and designers. Initially, the majority of these reports were classified due to the defense related and company proprietary content and hence much material has not been available in the public domain. An example of such a report is shown in Figure 1. A NASA technical document had been published in 1963 and it was declassified in 1972, describing aerodynamic characteristics of the Dyna-Soar glider. ${ }^{11}$ This type of report is mostly mathematical in nature, it provides

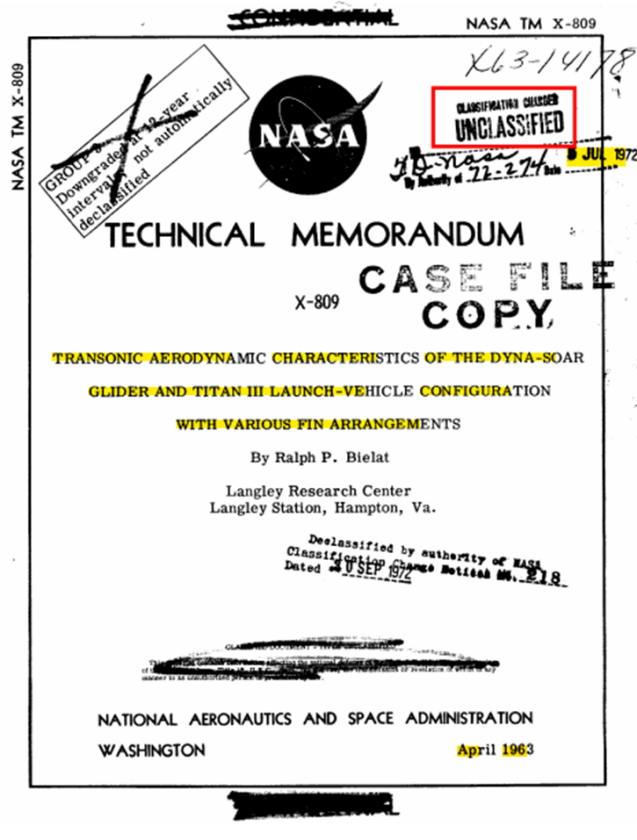

Figure 1: Example: Technical Report precise details of the methods and results, and is a valuable data source for discipline specific researchers.

At the same time, numerous books, research papers and journal articles have been published which discuss these legacy programs at a very top-level, highlighting major contributions and lessons learned, aspects which are usually not addressed in typical discipline-specific technical reports. These sources could be described as historiography accounts of the hypersonic research and contain only the most important results from the original technical reports. It should be noted that in the current context, only the literature sources which document multiple programs are considered as historiography sources since the focus of content is on the evolution of the hypersonic knowledge and not on a single specific case study. This historiography literature is of value as it provides a holistic overview of projects and programs whilst highlighting the quality and level of research conducted for classical disciplines. These sources tend to provide a guideline for 
researchers to identify those historical projects relevant to their specific research discipline. The following discussion highlights some of the important hypersonic historiography sources, which are also the inspiration for developing the proposed methodology.

i. Program oriented - Comprehensive surveys : This category of literature includes research articles and books where the discussion is directed towards historical hypersonic programs of national and international origin. These surveys are not restricted to any one particular discipline or organization and are some of the most comprehensive accounts. Although multiple such surveys exist, there is no single source which could be said to cover each and every hypersonic research activity comprehensively.

Dr. Richard Hallion's research paper "History of Hypersonics" 8 is one of the best examples of this category and one of the most comprehensive accounts of hypersonic research history. This paper is a follow-up on his previously published three volumes account "The Hypersonic Revolution: Case Studies in the History of Hypersonic Technology", ${ }^{12-14}$ which discuss fewer programs than the paper but it provide more details. A few other notable authors like Hirschel, ${ }^{7}$ Springer, ${ }^{9}$ Bille et al ${ }^{15}$ have published similar accounts of hypersonic history. Erbald ${ }^{6}$ provides a comprehensive review of the active and near term national and international programs in 2004 and is a more recent account of hypersonic vehicle development.

Apart from these research papers, a number of books also fall under this category of literature. Bill Rose's "Secret Projects: Military Space Technology" 16 is another extensive survey of international aerospace programs, that also includes some lesser known concepts. Asif Siddiqi also deserves a special mention for "Challenge to Apollo"17,18 as the definitive history of the Soviet manned space program. Other notable books in this category are included in references. ${ }^{19-25}$

ii. Program oriented - Selective surveys: Unlike the sources in first category, some research papers discuss a specific group of programs which were part of either one organization or belong to the same class of vehicles. Hansen ${ }^{26}$ and Reubush's ${ }^{27}$ accounts of Hypersonic research at NASA Langley and Draper's ${ }^{28}$ review of activities of the Flight Dynamics Laboratory in hypersonic configuration research are examples of historiography of US based research organizations. Tolle ${ }^{29}$ provides a "Review of European aerospace transporter studies" prior to 1967 and Wuest's "Review of German work on controlled re-entry technology" 30 in 1983 are, some rare documents providing a peek into early hypersonic international efforts. An officially unpublished report by Becker" (as referred on NASA website) titled "The Development of Winged Reentry Vehicles 1952-1963" is a collection of important findings from programs and studies aimed towards development of winged reentry vehicles. Books like "Testing Lifting Bodies at Edwards" 32 and "Wingless Flight" 33 are historical first hand experiences of engineers involved in development of lifting body shapes at NASA Langley and are focused only on the lifting body configuration. Becker ${ }^{34}$ provides accounts of NASA's pioneering development in spaceflight research. A similar extensive account of major European research efforts is also provided by Kuczera. ${ }^{35}$

iii. Discipline oriented surveys: This category of literature refers to articles and papers which survey classical disciplines involved in hypersonic vehicle design. These sources address research developments from a disciplinary-oriented point of view and discuss projects which were important for every discipline. Bertin and Cummings ${ }^{36}$ reviews the history of hypersonic vehicle development in terms of programs that made significant contributions towards aerothermodynamics, propulsion and structures disciplines, with brief discussion of fundamental scientific principles and critical breakthroughs in every discipline. Another research paper by the same authors titled "Critical Hypersonic Aerothermodynamic Phenomena" 37 is a survey of analytical and numerical methods developed in aerothermodynamics with relevant references to key projects. Several other similar discipline based historiography sources are included in references. ${ }^{38-40}$

In today's digital world, a large number of websites, digital archives, and technical forums hold equal information regarding the hypersonic history, although most websites and digital accounts are based on sources similar to those mentioned in the above three categories. Readers are encouraged to visit NASA History Programs Office's website ${ }^{41}$ for further accounts of historical projects, particularly the NASA History Series of publications.

As highlighted by the literature review, a wide and varied body of literature is present documenting the rich legacy of the past. However, these literature sources are vast and generic in account of the description of legacy projects. The discussion of a project tend to be qualitative in nature addressing the achievements, 
lessons learned and technical characteristics of the vehicle and sub-systems and the processes involved. The importance of a project and the impact on achievements, lessons learned, and data-richness generated is accounted in a stand-alone manner. There is no single account which attempts to analyze and compare these historical programs against each other whilst providing a quantitative measure of importance of particular projects towards the growth of particular disciplines and its holistic contribution to the hypersonic knowledge base. As a result, these accounts clearly carry data, information and knowledge of undisputable value, making them invaluable resources towards the formulation of a pragmatic knowledge-capture framework.

This study is utilizing the information that the above mentioned historiography literature sources do provide. These sources are the foundational building blocks utilized for the present study to identify related LRV technical evolution. The objective is to extract such information which provides insight into the disciplinary and systems level contributions by a program towards hypersonic knowledge evolution. To this effect, a comprehensive database has been prepared where information is categorized for individual vehicles. This information has been utilized to develop a numerical framework where the vehicles are assessed for discipline contribution, see Figure 2. The following section describes the rationale to select the case-studies assessed for this study.

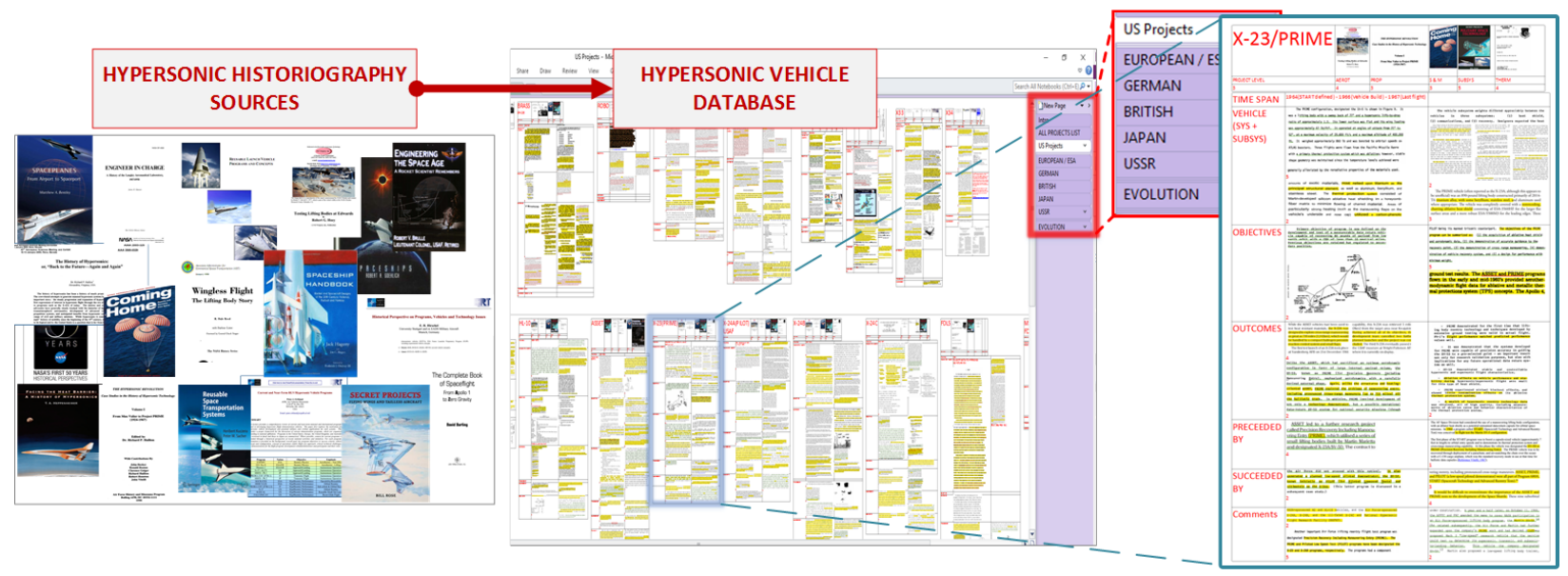

Figure 2: Hypersonic Historiography-Sources Application

\section{B. Case-Studies Selection}

Space Access Systems can be classified into various categories based on vehicle configuration, operational considerations and technology implementation. Hirschel notes in reference[7]: "Usually issues of hypersonic flight are discussed while not taking into account, that big differences exist between flight of pure re-entry vehicles and flight of airbreathing vehicles. It is, however, beneficial to define classes of hypersonic flight vehicles in view of their different design and technology features."

Following this logic, four types of hypersonic vehicles are defined in "Basics of aerothermodynamics": 42

i. Lifting reentry vehicles (LRV): Space Shuttle, BURAN, HERMES, X-38, ...

ii. Airbreathing cruise and acceleration vehicles (CAV): lower stages of TSTO systems, eg. Sänger, Spiral, $\ldots$

iii. Airbreathing ascent and re-entry vehicles (ARV): NASP/X-30, HOTOL, ...

iv. Aeroassisted orbital transfer vehicles (AOTV)

Figure 3 shows the operating environment conditions and characteristic features of these four vehicle types which dictates primary design requirements for each category. Lifting reentry vehicles are proven to be more effective and efficient over conventional ballistic-reentry-type capsules. Performance calculation studies by Eggers et al, ${ }^{3}$ Galman, ${ }^{43}$ and Love ${ }^{44}$ have established performance and operational advantages of the horizontal landing vehicles over ballistic reentry capsules. Dissel et al, ${ }^{45}$ Berry ${ }^{46}$ and others have shown how the horizontal landing lifting reentry vehicles are the next logical step to develop a fully reusable system in comparison with high-technology demanding SSTO air-breathing options. 
Consequently, this study will consider only lifting reentry vehicles as the case-studies to demonstrate the proposed methodology. The historical projects, programs and paper studies that are directed towards developing a lifting re-entry vehicle are selected to be reviewed and assessed based on disciplinary contribution.

It must be noted here that CAV and LRV vehicles share certain common mission traits, an overlap among these vehicle types has been observed in concepts like aforementioned SängerII . The following remark by Hirschel's ${ }^{7}$ explains this common ground:"We use in the following chapters $R V$-type and $C A V$-type flight vehicles as reference classes. All shades in between are possible." As a result, some case-studies might not adhere strictly to LRV class only but overlap with the CAV class as well. The Sänger $\mathrm{II}^{47}$ vehicle is such an example where Horus, the second stage glider was an LRV while the first stage was a CAV. ${ }^{35}$ After an extensive survey of the historiography literature, sixty world-wide LRV programs are selected as case studies to be assessed in the present study. These are shown in Table 1.

\section{Methodology}

The case studies identified in the Table 1 are analyzed using an analytical method, developed by modifying the traditional AHP technique. First, a description of the fundamental AHP method is presented. Then, the specific changes as applied for the current study are given and finally, the section concludes with an overview of the prototype model developed.

\section{A. Analytic Hierarchy Process}

The Analytic Hierarchy Process (AHP) is an effective technique developed by Thomas Saaty ${ }^{48}$ in 1980 to deal with the problems encountered in complex decision making. The basic concept is to breakdown a complex decision into a series of simpler decisions. This type of approach is particularly useful for analyzing problems where qualitative and non-tangible aspects are of significant worth. The AHP captures the qualitative essence and provides a measurable quantitative framework which enables consistent informed decisions.

\section{How AHP works}

For a clear understanding of the AHP methodology, it is required that the reader is familiar with certain standard terminology. The following descriptions of the basic elements of an AHP model is given for this purpose.

Alternatives: An alternative is what is being judged by the process. The AHP evaluates certain options or alternatives to decide which alternative is the best by developing a numerical ranking system among the alternatives.

Evaluation Criteria: Criteria are a group of factors to be taken into consideration while making the decision. Each criterion represent a factor which captures objective or subjective attributes of the final decision and influence the decision making process. The decision for every alternative is made by taking into account all the evaluation criteria. A complex decision is complex because it is based on 
Table 1: List of LRV Programs Selected as Case-Studies for Assessment

\begin{tabular}{|c|c|c|c|c|}
\hline Projects & $\begin{array}{l}\text { Start } \\
\text { Year }\end{array}$ & End Year & Organization & Manufacturer \\
\hline \multicolumn{5}{|l|}{ US } \\
\hline Tsien Spaceplane & 1949 & 1949 & $\mathrm{~N} / \mathrm{A}$ & $\mathrm{N} / \mathrm{A}$ \\
\hline BOMI & 1952 & 1954 & USAF & Bell \\
\hline BRASS & 1956 & 1956 & USAF & Bell \\
\hline HYWARDS & 1956 & 1957 & USAF & NASA Langley \\
\hline ROBO & 1956 & 1957 & USAF & Bell/Convair/Douglas/NAA \\
\hline $\mathrm{X}-20$ & 1957 & 1963 & USAF & Boeing \\
\hline Alpha Draco & 1957 & 1959 & USAF & Douglas \\
\hline RTTOCV & 1962 & 1964 & NASA & Lockheed/Convair/NAA/Douglas \\
\hline M2 & 1962 & 1973 & NASA/USAF & Northrop \\
\hline ASSET & 1963 & 1965 & USAF & McDonnell \\
\hline HL-10 & 1964 & 1970 & NASA & Northrop \\
\hline X-23/SV5D/PRIME & 1965 & 1967 & USAF & Martin \\
\hline $\mathrm{X}-24 \mathrm{~A} / \mathrm{SV}-5 \mathrm{P} / \mathrm{PILOT}$ & 1965 & 1971 & USAF/NASA & Martin \\
\hline ILRV & 1967 & 1968 & USAF & Lockheed/GD/McDD \\
\hline FDL-5 & 1968 & 1969 & USAF & Lockheed \\
\hline BGRV & 1968 & 1969 & USAF & McDonnell \\
\hline Reentry-F & 1968 & 1968 & NASA & General Electric \\
\hline $\mathrm{X}-24 \mathrm{~B} / \mathrm{FDL}-7$ & 1971 & 1973 & USAF/NASA & Martin Marietta \\
\hline STS & 1972 & 2011 & NASA & North American/Rockwell \\
\hline $\mathrm{X}-24 \mathrm{C} / \mathrm{FDL}-8$ & 1973 & 1977 & USAF & Lockheed \\
\hline RASV & 1976 & 1977 & USAF & Boeing \\
\hline ALSV & 1979 & 1983 & USAF & Boeing/Rockwell/GD \\
\hline SWERVE & 1979 & 1985 & USAF & Sandia \\
\hline TAV & 1983 & 1995 & USAF & Lockheed/GD/McDD/Rockwell \\
\hline HL-20 & 1988 & 1993 & NASA & Rockwell International \\
\hline Pioneer Pathfinder & 1993 & 2001 & USAF & Pioneer Rocketplane \\
\hline $\mathrm{X}-33$ & 1995 & 2001 & NASA & Lockheed Martin \\
\hline $\mathrm{X}-34$ & 1995 & 2001 & NASA & Orbital Sciences Corporation \\
\hline $\mathrm{X}-38$ & 1995 & 2002 & NASA & Scaled Composites \\
\hline $\mathrm{X}-37$ & 1998 & ongoing & USAF/NASA & Boeing \\
\hline DreamChaser & 2005 & ongoing & NASA & Sierra Nevada Corporation \\
\hline \multicolumn{5}{|l|}{ ESA } \\
\hline Hermes & 1984 & 1992 & CNES/ESA & Arospatiale/Dassault-Breguet \\
\hline FESTIP & 1994 & 1998 & ESA & $\mathrm{N} / \mathrm{A}$ \\
\hline PRE-X & 2000 & ongoing & CNES & EADS LV \\
\hline Phoenix & 2000 & 2004 & ASTRA & Pacific American \\
\hline EXPERT & 2002 & ongoing & ESA & Thales Alenia \\
\hline USV & 2004 & ongoing & ESA/CIRA & CIRA \\
\hline SOCRATES & 2004 & N/A & ESA & $\mathrm{ESA} / \mathrm{DLR}$ \\
\hline IXV & 2005 & ongoing & ESA & Thales Alenia \\
\hline \multicolumn{5}{|l|}{ Germany and UK } \\
\hline Silverbogel & 1933 & 1942 & $\mathrm{~N} / \mathrm{A}$ & $\mathrm{N} / \mathrm{A}$ \\
\hline Whitworth Pyramid & 1954 & 1960 & $\mathrm{~N} / \mathrm{A}$ & $\mathrm{N} / \mathrm{A}$ \\
\hline JunkersRT-8 & 1961 & 1969 & Junkers & Junkers \\
\hline MUSTARD & 1962 & 1968 & $\mathrm{BAC}$ & $\mathrm{BAC}$ \\
\hline BUMERANG & 1967 & 1974 & ERNO & ERNO \\
\hline SangerII/HORUS & 1985 & 1995 & MBB & MBB \\
\hline PLATO & 1987 & 1990 & MBB-ERNO & MBB-ERNO \\
\hline \multicolumn{5}{|l|}{ Japan } \\
\hline OREX & 1994 & 1994 & JAXA & NASDA \\
\hline HYFLEX & 1996 & 1996 & JAXA & Mitsubishi Heavy Industries \\
\hline AFLEX & 1996 & 1996 & JAXA & Mitsubishi Heavy Industries \\
\hline HSFD & 2000 & 2004 & JAXA & Mitsubishi Heavy Industries \\
\hline \multicolumn{5}{|l|}{ USSR/Russia } \\
\hline VKA-23 & 1956 & 1959 & OKB-23 & Myasishchev \\
\hline OKB-Racketoplan & 1959 & 1962 & OKB-53 & Chelomey \\
\hline SPIRAL-OS & 1962 & 1975 & OKB-155 & Mikoyan \\
\hline Mig-105 & 1976 & 1978 & USSR Air Force & Mikoyan \\
\hline BURAN & 1976 & 1988 & NPO Molnia & Mikoyan \\
\hline BOR-4 & 1980 & 1984 & NPO Molnia & NPO Molnia \\
\hline LKS & 1980 & 1983 & Chelomey & Chelomey \\
\hline MAKS & 1988 & 1991 & NPO Molniya & NPO Molniya \\
\hline ORYOL & 1993 & 2001 & RSA & RSA \\
\hline KLIPPER & 2004 & 2007 & RSA & RSC Energia \\
\hline
\end{tabular}


multiple variable criteria. AHP quantifies the qualitative criteria that can now be used as variables in an equation.

Pair-wise comparison: A user-defined measure of one object (criteria or alternative) against another object of the same type, based on a standard scale. Saaty ${ }^{48}$ defines a comparison scale where a higher value represent a higher importance. In the AHP technique, every object is measured with all other objects of the same type, in a pair-wise comparison.

Criteria Weight: Criteria are the factors to be accounted in the final decision but not every criteria is equally important. The criteria weight is a numerical figure representing importance of a criteria in the final decision and is obtained by pair-wise comparison among all the criteria.

Alternative's Score: Each alternative is assigned a score for every criteria quantifying its strength or weakness for that criteria. This scoring is independent of criteria weights and is done by pair-wise comparison among all the alternatives.

Global Score: The global score is a combination of criteria weights and alternative scores and is calculated for every alternative. It establishes the final ranking of alternatives for the final decision.

AHP is applied in situations where a set of alternatives are evaluated based on certain evaluation criteria. Through a pair-wise comparison among all the ' $\mathrm{n}$ ' number of criteria, an ' $\mathrm{n} x \mathrm{n}$ ' comparison matrix is developed. By first normalizing the matrix and then averaging each row, eigen values and eigen vector assessment is performed to determine the weight of each criteria. This process enforces a consistency check on the criteria weight to avoid any user-defined bias among the evaluation criteria. If this consistency check is not met, the initial comparison matrix has to be to re-evaluated. Alternative's scores are also calculated through the same process. These two steps, though similar in execution, are independent of each other. The global score for each alternative is now used to select the best alternative. A detailed explanation of the above explained process is found in reference [48].

\section{AHP Illustrative Example}

A simple example is used here to demonstrate the AHP methodology. Let us consider a simple case where Thomas has to pick one out of four universities (A, $\mathrm{B}, \mathrm{C}$ and $\mathrm{D}$ ) for his undergrad studies. Thomas identifies three criteria that will form the basis for his final decision. The three criteria are prioritized after pairwise comparisons. These three criteria along with their respective weight are as follows:

i. Tuition Fee $($ Weight $=0.48)$

ii. Reputation of the University (Weight $=0.35)$

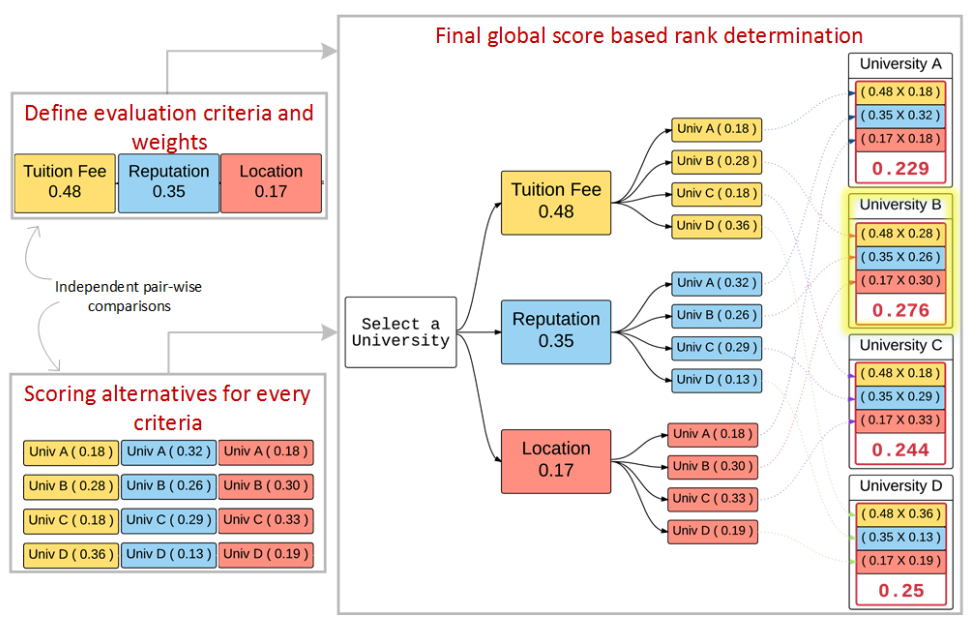

iii. Location of the Campus (Weight $=$ 0.17 )

Figure 4: AHP Example

It is apparent from the list that all the

factors are not equally important while making this decision. Now he has to choose out of four options (A, $\mathrm{B}, \mathrm{C}$ and D), which university is best for him based on the above defined criteria. Every alternative has certain advantages for some criteria and disadvantages for others.

For example, University A is the most reputed but has high tuition fee and poor campus location compared to other options. Based on these characteristics, all four options are scored for each criteria and a global score is generated to rank each university. Through this process, AHP provides an analytical framework to 
quantitatively assess all factors and provide a numerical result to help Thomas select the best university. Figure 4 visualizes the example and the AHP method.

The example used is a very simple illustration of the fundamental idea implemented by the AHP but demonstrates the wide applicability aspects of the method. If the qualitative factors are clearly defined, the AHP can be used to assemble a logical framework and provide a quantitative measuring scale. At the same time, the complexity of the model grows with the number of criteria and alternatives as they represent the total number of pair-wise comparisons. For this current study, case-studies listed in Table 1 are the alternatives while the criteria to evaluate them are defined in following sub-section.

\section{B. Selecting Evaluation Criteria}

A space access vehicle is a multi-disciplinary system, where constituent sub-systems integrate cohesively to perform a mission as per the program requirements. The legacy projects being assessed here could be broadly categorized as either technology oriented or vehicle oriented. It is observed that the primary disciplines involved in design of space access vehicles serve as suitable criteria. These disciplines are the basis of most technology oriented programs and are also the building blocks of a SAS design. By defining the disciplines as evaluation criteria, it will be possible to distinctly recognize the contribution of each casestudy towards an individual discipline. Technology development programs, which tend to focus on one or two disciplines, would receive high scores for those disciplines.

At the same time, it is also necessary to consider the quality and depth of research achieved by a casestudy. To include this factor in the model, an additional criterion is added based on the life-cycle stage reached by the case-study.

Hirschel $^{7}$ provides a list of requirements on classical hypersonic disciplines, defined for the FESTIP Technology and Development Plan. ${ }^{49}$ Based on this list, five primary hypersonic disciplines are identified as disciplinary evaluation criteria for the current model. Definition of these criteria is selected form Hirshel, ${ }^{7}$ and modified to suit the current study. A sixth criterion is selected to identify the progress of a project at a systems level. The six evaluation criteria are defined below:

\section{Disciplinary Criteria}

i. Aerothermodynamics: aerodynamic performance, configuration flyability qualities, propulsion/airframe integration, (upper) stage integration and separation for TSTO-systems, loads determination, surface properties determination.

ii. Structures and materials: structural topology, light-weight primary structures, hot stabilisation and control surfaces, cryo-tank structures(integrated/non-integrated), materials, coatings, joints, seals.

iii. Propulsion: propulsion system performance analysis, weight, reusability, throttleability (landing engines), restartability, fuel consumption, propulsion/airframe integration, net thrust, cooling (inlet, core engine, nozzle).

iv. Subsystems: flight mechanics/dynamics, stability and controllability, flight control system, airdata system, general instrumentation, actuator systems, guidance navigation and control, stage separation system for TSTO-systems, onboard power generation.

v. Thermal management: TPS addressed, heating analysis, passive (surface radiation) cooling, internal insulation, active cooling (internal, external), thermal household of CAV-type vehicles.

\section{System-Level Criteria}

vi. Project Level: paper study, ground test, flight test, technology demonstrator, operational vehicle.

These six evaluation criteria are the parameters to judge the selected group of case studies. Each disciplinary criteria is defined as a group of specific analysis requirements to easily identify the research progress achieved by a case-study in every discipline. By following this definition pattern, every case-study can be consistently

scored for a criterion by matching the number of analysis requirement satisfied by that case-study. This rationale is further explained in following sub-section. 


\section{Defining Scoring-Metric for Case-Studies}

According to the standard AHP technique, every case-study must be scored through a pair-wise comparison with other candidates, for each evaluation criteria. Doing so establishes a consistent measure by breaking the complex decision involving all alternatives, into a series of easy decisions among two alternatives at a time. Such pairwise comparison breakdown is easily applicable for a small model where the number of combinations of criteria and alternatives is relatively limited. For an AHP model, if 'A' is the number of alternatives and ' $\mathrm{C}$ ' is the number of criteria, then the total ' $N$ ' pair-wise decisions among alternatives is calculated as:

$$
N=C *\left(A^{2} / 2-A\right)
$$

For the illustrative example used to explain AHP method, 27 pair-wise comparison are prepared by the user (See Figure 4). The total number of pairwise decisions grows exponentially with the number of alternatives. For the current study where the model is composed of 6 evaluation criteria and 60 alternatives, the total number of pairwise decision becomes 10,440. To mitigate this overwhelming task of comparing one casestudy against others, a simplistic approach is adopted where all the case studies are scored against a standard baseline. In this manner, all the case studies are measured consistently requiring a short turaround time, given the reference point is clearly and distinctly defined.

This baseline is established through a scoring metric based on the definition of the evaluation criteria. A scoring scale is defined for all six criteria such that a higher score indicates that the alternative meets most analysis requirements from the criteria definition. The scoring metric is given in Table 2 describing what each score entails for a criterion.

Table 2: Case-Studies Scoring Metric

\begin{tabular}{|c|c|c|}
\hline Score & Disciplinary Criteria Description & System-Level Criteria Description \\
\hline 1 & $\begin{array}{l}\text { Discipline not evaluated in case-study } \\
\text { Meets no definition requirements } \\
\text { No impact on the project }\end{array}$ & $\begin{array}{l}\text { Paper Study: Preliminary design analysis } \\
\text { performed, data not available to confirm existence } \\
\text { of ground tests hardware }\end{array}$ \\
\hline 2 & $\begin{array}{l}\text { Minimal impact on the project } \\
\text { Minimal definition requirements } \\
\text { Not important for the project }\end{array}$ & $\begin{array}{l}\text { Ground Test: Detailed design analysis supported } \\
\text { by ground-test articles dedicated for specific } \\
\text { disciplines(Wind Tunnel Models, Simulator etc.) }\end{array}$ \\
\hline 3 & $\begin{array}{l}\text { Satisfy all definition requirements } \\
\text { Not important for the project } \\
\text { Not gained anything new } \\
\text { Used off-the-shelf technology }\end{array}$ & $\begin{array}{l}\text { Flight Test: Program carried out flight tests } \\
\text { focusing on design-tool validation dedicated for } \\
\text { specific disciplines (Scaled Flight Test Model) }\end{array}$ \\
\hline 4 & $\begin{array}{l}\text { Satisfy all definition requirements } \\
\text { Has a major impact on the project } \\
\text { Significant results gained } \\
\text { Uses state-of-art technology } \\
\text { Influence on future programs }\end{array}$ & $\begin{array}{l}\text { Technology Demonstrator: Scaled version of the } \\
\text { targeted operational vehicle, focusing on the } \\
\text { integration and validation of key technologies at } \\
\text { systems level }\end{array}$ \\
\hline 5 & $\begin{array}{l}\text { Satisfy all definition requirements } \\
\text { Key discipline driving the project } \\
\text { Breakthrough results gained } \\
\text { State-of-art technology development } \\
\text { Project significant to discipline's growth } \\
\text { New lessons learned } \\
\text { Directly applied to future programs }\end{array}$ & $\begin{array}{l}\text { Operational Vehicle: Vehicle ready to perform } \\
\text { transpiration tasks from orbit and back. Only } \\
\text { three vehicles from the case-studies have reached } \\
\text { operational level(US Space Shuttle, USSR Buran } \\
\text { and X-37). }\end{array}$ \\
\hline
\end{tabular}

Scoring scale for the systems criteria ("Project Level") is relatively much easier to understand and implement than disciplinary criteria.As seen in figure 5 , this criteria follows the product life-cycle stages, represented here by a standard V-Model. ${ }^{50}$ The disciplinary criteria are scored based on the multiple factors, like

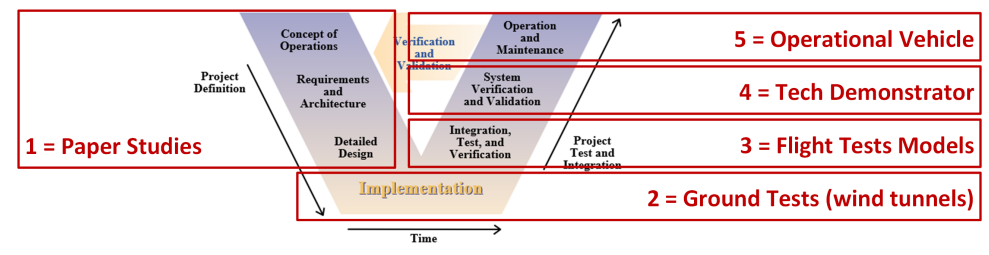

Figure 5: Project Level Criteria Scoring 
the level of research effort addressed by a case-study for the discipline, impact of the discipline on the case study, contributions of the case-study to discipline's knowledge growth etc. So, for a case-study where CFD analysis of the vehicle is performed, it would get a higher score in 'Aerothermodynmics' criteria over another case-study where the aerodynamics analysis is limited to a basic lift-drag polar.

In order to appropriately score the disciplinary criteria, every case-study is examined thoroughly by reviewing the available information for every discipline. This goal is achieved by an exhaustive literature survey, followed by structured organization of the information. For this purpose, the hypersonic database is developed from the historiography sources as explained earlier in the literature review section (Figure 2).

\section{Determination of Evaluation Criteria Weights}

For the traditional AHP technique, the criteria weight is evaluated by a user-defined, pairwise comparison among evaluation criteria. The complexity of this particular study lies in defining the importance among disciplinary criteria, as a specific discipline could be important in one project while not equally important for the other. An example of this difference is seen in case-studies like ASSET and PILOT, both part of the same START program ${ }^{22}$ but with very different mission requirements and thus different vehicle designs. The ASSET project was aimed to develop aerothermodynamics and structures \& materials for X-20 program. ${ }^{12}$ On the other hand, PILOT or X-24A explored the problem of maneuvering entry to demonstrate stable and controllable flight characteristics. ${ }^{12}$ While assigning criteria scores for both these case-studies, ASSET is scored highly for 'aerothermodynamics', 'structures \& materials' and 'thermal management' disciplines while PILOT is scored highly for 'subsystems'. Similarly, every case-study has specific requirements, mission objectives and operational constraints which dictate the level of involvement and growth for different disciplines. Therefore, one disciplinary criteria cannot be arbitrarily assigned more or less important than another, as it would create a inherent unjustified bias in the evaluation model. To resolve this complexity, a different approach has been taken to generate the initial comparison matrix, than the standard AHP process of manually assigning one criteria more important than other. The mathematical process following this first step is the same as implemented in the AHP logic, which enforces the consistency check on the final criteria weights.

Table 3: Criteria Weights

\begin{tabular}{lcc}
\hline Criteria & First Iteration Weight & Final Weight \\
\hline $\begin{array}{l}\text { System-Level Criteria } \\
\text { Project Level }\end{array}$ & 0.374 & $\mathbf{0 . 3 0 8}$ \\
Disciplinary Criteria & & \\
Aerothermodynamics & 0.139 & $\mathbf{0 . 1 5 7}$ \\
Propulsion & 0.107 & $\mathbf{0 . 1 1 4}$ \\
Structures and Materials & 0.128 & $\mathbf{0 . 1 3 2}$ \\
Subsystems & 0.123 & $\mathbf{0 . 1 3 6}$ \\
Thermal Management & 0.129 & $\mathbf{0 . 1 4 4}$ \\
\hline
\end{tabular}

The criteria defined for this study are classified into two broad categories: (1) Systems-Level criteria and (2) Disciplinary criteria. 'Project level' criteria being a systems level factor, is held three times more important than disciplinary criteria, which are representative of sub-system advancement. To develop the comparison matrix among disciplines, every case-study is scored for all disciplinary criteria and a cumulative total is calculated for each discipline. Since the disciplinary criteria score for a case-study represents the contribution and significance of that discipline, the cumulative scores thus represents the overall research effort of all case-studies towards a discipline. As a result, cumulative discipline scores reflect the trend shown by the case-studies throughout the evolution of the hypersonic knowledge base and are used to make pair-wise relations among disciplines that leads to the first set of criteria weight based on an acceptable consistency check. The first iteration of the criteria weighs are used again, combined with the disciplinary case studies scores to implement a feedback loop and provide a second iteration of criteria weights. These weights are used as the final criteria weights while executing the AHP process. The priority among criteria is then established as reflected in the final weights. The final calculated weights are given in Table 3 where it can be seen that Project Level is assigned maximum weight over other disciplinary criteria, while the five 
disciplinary criteria are relatively close to each other as indicated by the cumulative discipline scores.

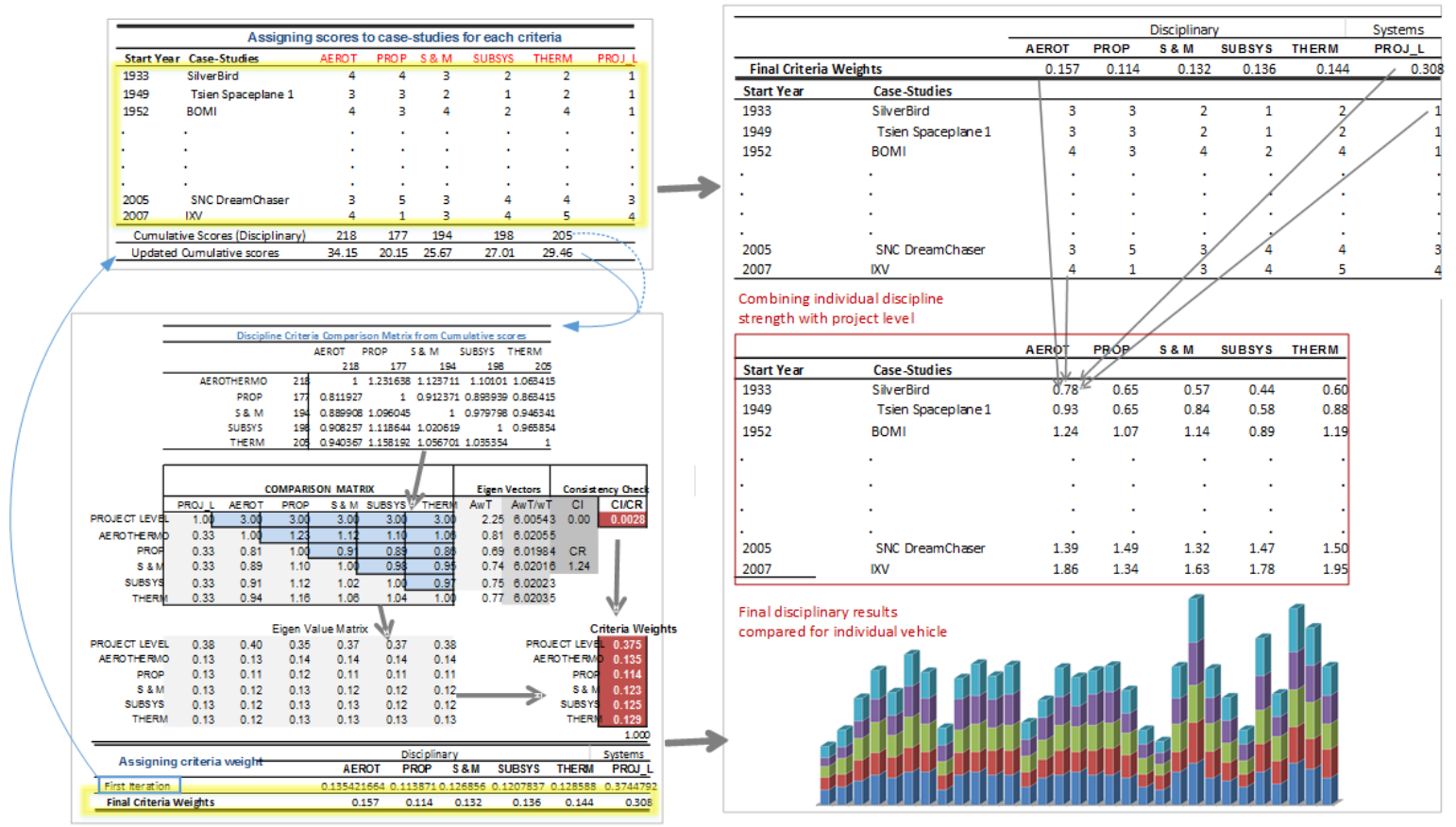

Figure 6: AHP model to evaluate selected case-studes

\section{E. Constructing Analytical Model}

At this point, all elements are in place to execute the AHP model. Every case-study is scored for all six evaluation criteria and final criteria weights are established. Case-study scores are multiplied by criteria weight for every criteria and added together to calculate a global score for every case-study. This score is indicative of the holistic contribution of every case-study towards hypersonic knowledge evolution. The model schematic is shown in Figure 6 where the information flow is visualized throughout the AHP process leading to the final comparative results for every case-study.

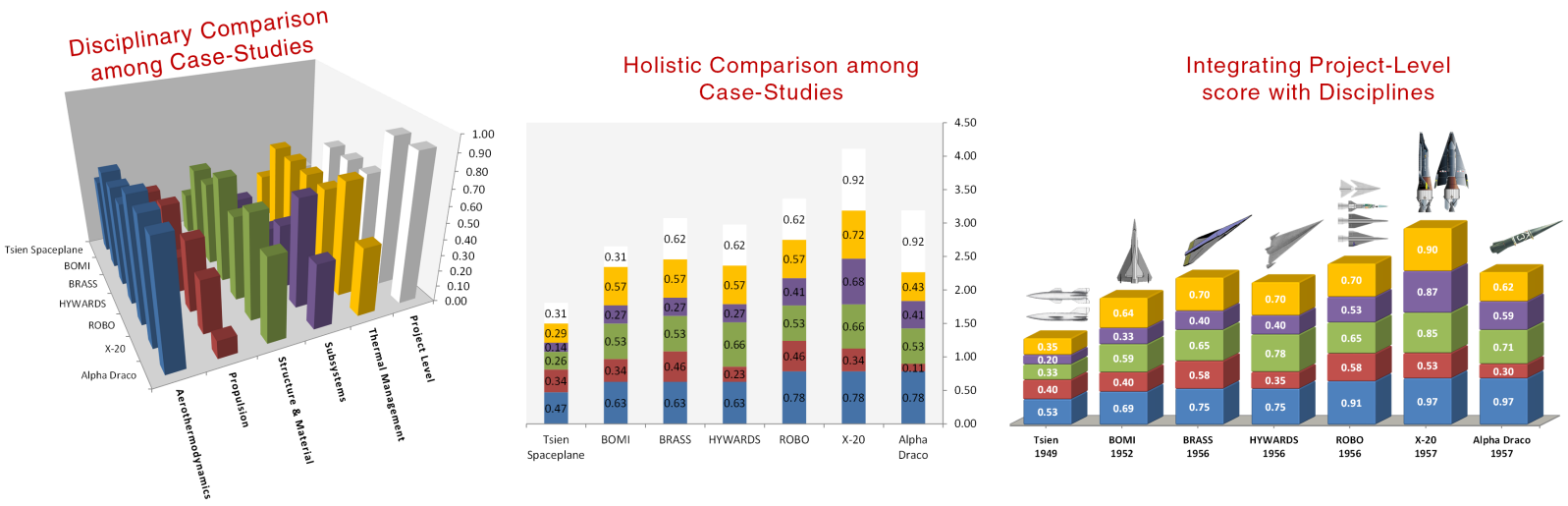

Figure 7: Results visualization

The AHP results could be used to analyze and compare case-studies for individual disciplines through which, a discipline-oriented researcher could visualize the most important historical programs for his own advantage. At the same time, the global score indicate holistic effects and importance of a program towards hypersonic knowledge evolution. A discipline-based global score is calculated next, such that the effect of 
the 'Project Level' criteria is distributed equally among the disciplines. This discipline-based global score is calculated as:

$$
D_{\text {Global-Score }}=D_{\text {Score }} * D_{\text {Weight }}+P_{\text {Score }} * P_{W e i g h t} / 5
$$

where $\mathrm{D}$ refers to a disciplinary criteria and $\mathrm{P}$ refers to Project-Level criteria. With this implementation, the global score for a case-study stays the same but the case-study could now be effectively represented as composed of only primary disciplines, see Figure 7

\section{US LRV Case-Studies Assessment: Tsien SpacePlane - SNC Dream Chaser}

The AHP model described in the last section, is applied to assess the LRV programs initiated in the United States of America, beginning with the 1949 Tsien's spaceplane concept, to the current day SNC Dream Chaser. A brief overview of every case-study is provided along with the AHP scores to identify the major contributions, and rationalize the disciplinary criteria scores assigned to every case-study. An evolution pattern is observed while assembling the LRV data-base as many case-studies are connected together, either under a common program structure, or through development and application of technology from one program to other. This commonality and connection is discussed with the results to chart the LRV design and technology evolution. Readers are advised to consult the common legend given in Figure 31 in Appendix A, while reading the result's visualization.

\section{A. 1950s: The X-20 Family}

Beginning of the US based LRV programs can be traced back to the period following operation Paperclip when, "Germans, primarily scientists but also engineers and technicians, were brought to the United States from Nazi Germany." ${ }^{51}$ Sänger's Silvervogel design was brought to the US as part of operation paperclip, when Hsue-shen Tsien, a USAF colonel at the time, was "sent by the Army to Germany to investigate the progress of wartime aerodynamics research. Qian investigated research facilities and interviewed German scientists including Wernher von Braun and Rudolph Hermann". ${ }^{2}$

Later, while working at Califormnia Institute of Technology in 1949, Tsien conceptualized a hypersonic research vehicle to be developed into a transcontinental rocket-liner. ${ }^{12}$ Although the concept was not feasible with the technology available at the time,${ }^{16}$ it is one of the first few proposals to document a lifting reentry concept applied to space access system. Contemporary with Tsien; Ehricke and Dornberger developed several LRV concepts in early 1952 while working at Bell Aircraft. ${ }^{53}$ These designs became the basis of the Bell BOMI concept, one of the first LRV projects undertaken by a major aerospace manufacturer of the time. BOMI was selected by the USAF in 1954 for the detailed design analysis, to investigate design and development problems associated with hypersonic flight regime. ${ }^{54}$

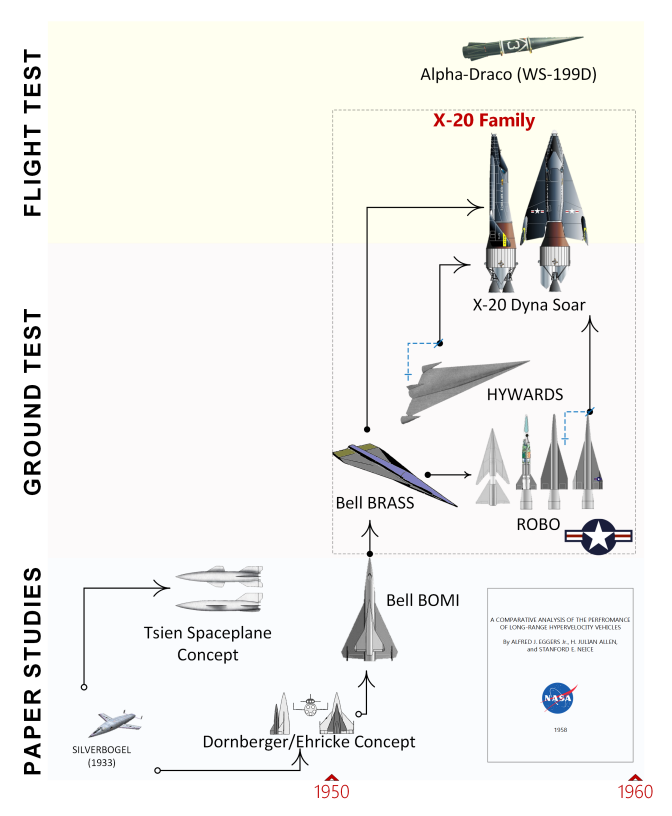

Figure 8: 1950s: LRV Evolution Under the USAF designation MX-2276, BOMI addressed detailed technical assessment of vehicle's aerodynamics, structure, propulsion and trajectory analysis, providing valuable guidelines for an operational LRV. ${ }^{55}$ Lessons learned during BOMI design development led the USAF to assign Bell with further investigation of a manned, hypersonic glide weapon system, under project BRASS in 1956. Bell improved on the BOMI design through wind tunnel tests and other experimental testing in propulsion, structures, aerothermodynamics and thermal management disciplines. ${ }^{56}$ BRASS incorporated these changes, and further tested and developed several state-of-art technologies in these four disciplines, with major emphasis on thermal active cooling techniques and effect of various propellant combinations. ${ }^{22}$ Around the same time, the USAF initiated studies to develop a piloted hypersonic Rocket Bomber(ROBO) and received proposals from Conviar, Douglas, Lockheed, NorthAmerican, Bell and Martin. Bell led the 
project, with experience gained during the research and experiments conducted for BRASS, which was also the basis of Bell's proposal for the ROBO. ${ }^{16}$ While ROBO and BRASS were targeted towards developing an operational hypersonic weapon system, it was realized that operational environment beyond $100 \mathrm{nmi}$ was essentially unknown. and needs to be understood before an operational vehicle could be developed. The USAF initiated project HYWARDS in 1956 for this purpose, with two very different vehicle concepts from NASA Langley(headed by Becker) and NASA Ames(headed by Allen and Eggers). ${ }^{26}$ HYWARDS studies contributed significantly towards understanding the aerodynamics and thermal characteristics of the hypersonic vehicle design. Hallion's quote further highlights HYWARDS' contribution:

"This was the first clear delineation of the possibility of aerodynamic design features which could significantly alleviate the heating and ease the hotstructures problems. Later application of these principles to actual flight systems was first made in the X-20 and they are also obviously applied in the current Space Shuttle."12

In 1957, the USAF decided to consolidate the details of BRASS, HYWARDS and ROBO programs into three steps of one single program under official designation X-20, later known as DynaSoar shortened for Dynamic-Soaring. ${ }^{57}$ This was one of the biggest venture undertaken by the USAF to develop a LRV. The X-20 program produced critical research breakthroughs that influenced future generations of LRV designs and technology. The program was cancelled in 1963 , just two months before the manufacturing phase began and the effort had already reached a budget of $\$ 410$ million. ${ }^{22} \mathrm{X}-20$ has been studied and docu-

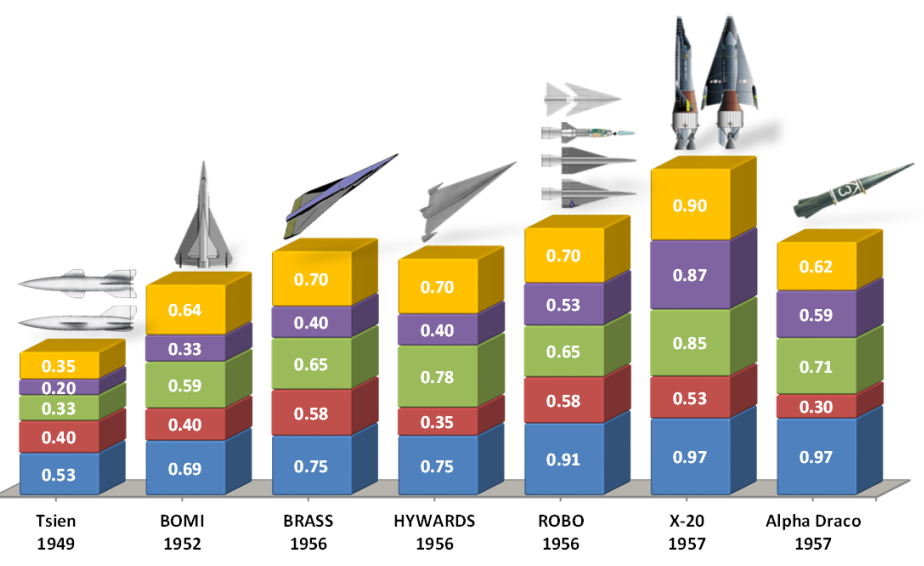
mented extensively by several historians and engineers alike as it is one of the 'what-if' programs that showed tremendous potential. Geiger, ${ }^{57-59}$ Houchins ${ }^{60}$ and Godwin ${ }^{4}$ have addressed X-20 program in great detail, thereby providing valuable contributions of the program that was utilized in LRV programs of the 1960s which directly influenced the development of the Space Shuttle. These accounts, along with several other historiography literature, mention the X-20 as a major milestone in the history of hypersonic research development. Rose remarks this as following:

"Dyna-Soar was certainly a very advanced piece of engineering, with many systems and innovations that would find their way into future aircraft and spacecraft."

Independent and contemporary of the X-20 program was McDonnell's Alpha-Draco, developed for the USAF as a part of the WS-199 project. It was a research vehicle to explore the feasibility of the boost-glide mission. Officially designated as WS-199D, Alpha-Draco yielded important data on the aerodynamics of hypersonic flight. Hallion describes the importance of Alph-Draco in following quotes:

"Alpha Draco was a little-known but significant step on the road to understanding the aerodynamic, heating, and maneuvering challenges of hypersonic flight." It anticipated later programs to acquire a data base on hypersonic reentry conditions, vehicle behavior, and flow characteristics (particularly boundary layer transition from laminar to turbulent flow, and its impact upon heating rates)." 8

The main highlight of the 1950s was the X-20 program for LRV design, which combined all previous efforts into one program. The final years of the decade witnessed a large number of ground tests and research activities undertaken towards understanding the hypersonic environment, and developing technology to meet the challenges imposed by the X-20 mission requirements. The AHP results for this decade are shown in Figure 9 


\section{B. 1960s: The Lifting Bodies}

Momentum gained with the X-20 program during the late 1950s was carried on in the early 1960s. While the X-20 evolved from Sänger's Silvervogel concept employing a delta-wing configuration, the lifting body design emerged from the feasibility and performance studies by Allen, Eggers and Neice. ${ }^{3}$ Although the lifting body configuration was examined by the USAF in the late 1950s under some preliminary studies, the real development of this design began during the early 1960s, which was also a declining phase for the X-20 program. Hallion comments on this transition of interest as follows:

"In June 1962, X-20A faced sniping criticism from partisans within the USAF Space Systems Division (SSD) favoring development of a rival-a small piloted lifting body for satellite inspection and space logistics known as SAINT II. Though Dyna-Soar weathered this storm while SAINT II itself succumbed, it was clear that Dyna-Soar was losing its appeal."12

Further discussion of LRV programs of the 1960s is addressing the families of vehicles developed in a common program.

\section{The RTTOCV Family}

NASA funded studies in 1962 for a "Reusable Ten Ton Orbital Carrier Vehicle" (RTTOCV), which represents a group of concepts by leading aerospace companies of the time. Several of these proposals were refined version of proposals submitted for ROBO and X-20 programs, while others like Douglas Astro were derived from the lifting body configurations developed by the NACA in the late 1950s. Heppenheimer describes some of the candidate concepts considered under RTTOCV study as follows:

"This study, called "Reusable Ten Ton Orbital Carrier Vehicle," awarded contracts of \$428,000 to Lockheed and of \$342,000 to NAA....Subsequent studies investigated additional alternatives and pursued design issues in greater depth. In 1965, General Dynamics defined a concept for a reusable second stage that had the shape of a lifting body...These studies concluded that, without exception, rocket engines were preferable to airbreathers for first-stage propulsion." 61

Martin's Astrorocket ${ }^{62}$ and Douglas' Astro ${ }^{63}$ are notable proposals under RRTOCV family which show advanced under-

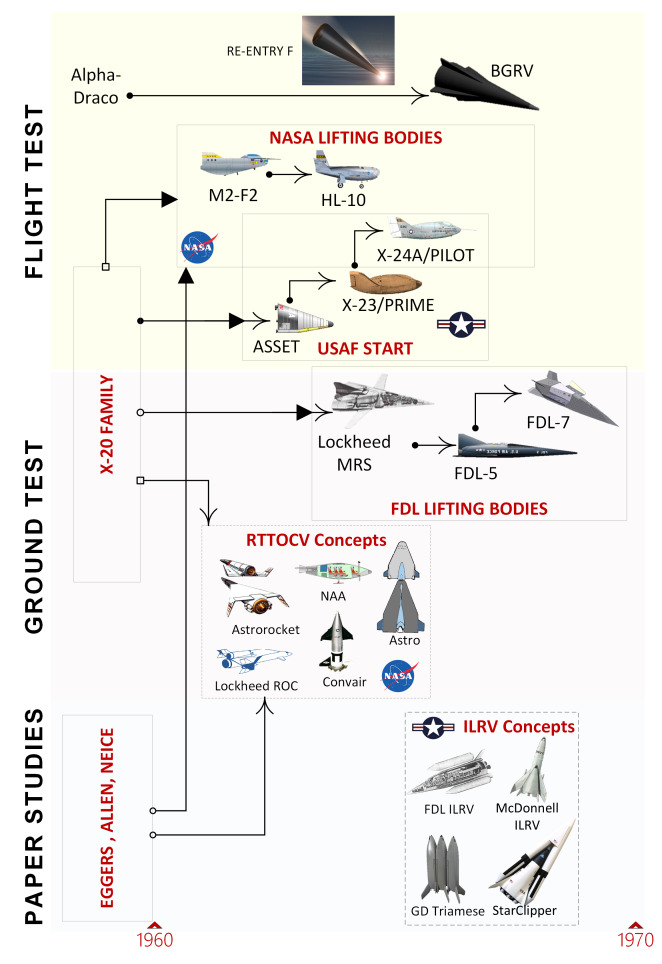

Figure 10: 1960s: LRV Evolution standing on systems feasibility and technology requirements for a fully reusable SAS. Reference [64] and [65] are NASA technical memorandum from 1967. They provide an overview of some of these concepts and lessons learned from a system feasibility point of view. Ultimately, they were influential while selecting vehicle configuration for the Space Shuttle. ${ }^{61}$ Since no detailed technical reports could be located for any of these proposals in the public domain (most likely due to company proprietary reasons), this group is considered as one case-study in the AHP model. Figure11 visualizes some important concepts reviewed under this family.

\section{NASA Lifting Body Program}

The NASA lifting body program began in 1962 with the M2 lifting body developed by Alfred J Eggers and associates at NASA Ames. Hoey describes this period as follows:

"From a NASA perspective, at least, the lifting body program had its beginnings in the studies of H. J. "Harvey" Allen, Alfred J. Eggers and others at the NACA Ames Aeronautical Laboratory in the early to mid-1950s into the blunt body reentry principle and the concept of lifting reentry from space. This predated Dyna-Soar. And it was these studies, plus roughly contemporary ones 
at the NACA Langley Aeronautical Laboratory on wingless lifting shapes, that led R. Dale Reed, a young engineer at the Flight Research Center, to advocate a flight research program involving lifting bodies." 32

What began as a wooden half-cone shell, quickly evolved to M2F1 following a series of wind-tunnel tests by adding control surfaces, and further to rocket powered M2-F2 and M2-F3 following a series of modification augmented by the flight test data from M2-F1. The M2 lifting body program was complimented by NASA Langley's HL-10 in 1964, developed to test safe reentry landing techniques. ${ }^{66}$ Both, M2 and HL-10 programs were significantly successful in demonstrating feasibility of lifting body configuration as a potential LRV and provided benchmark results in aerothermodynamics and subsystem disciplines for lifting bodies. The flight test data and lessons learned from these programs were critical in influencing many design features in the Space Shuttle. ${ }^{16,22}$ Hallion quotes:

"Clearly the M2 and HL-10 efforts constituted an important approach to hypersonic flight technology, even though they themselves never approached hypersonic velocities."13

While NASA Langley was still performing test flights for HL-10, another lifting body project, the $\mathrm{X}-24 \mathrm{~A}$ was initiated at Edwards

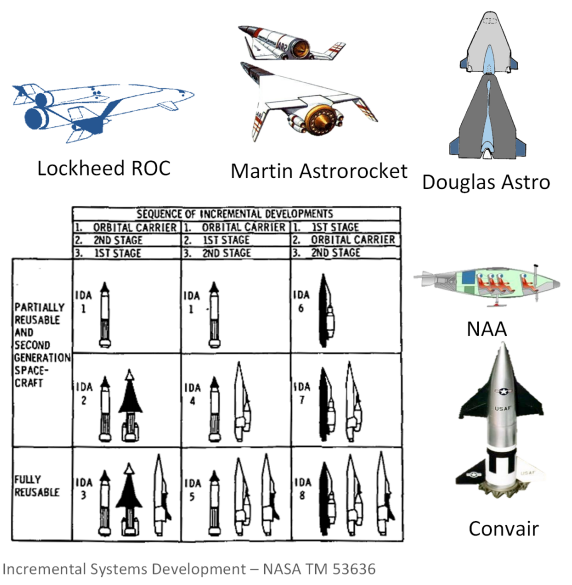
under the NASA-USAF collaboration in 1965. The USAF has been independently testing lifting bodies since the late 1950s, which evolved into the START program in the early 1960s. The X-24A was based on Martin SV-5P lifting body, which was originally designated as the PILOT under the USAF START program. ${ }^{32}$ In this regards, X-24A/SV-5P/PILOT represents one of the first major joint venture between NASA and USAF. Major contributions of the X-24A were in the discipline of subsystems development by improving on the stability and control features of the lifting body design. Accomplishment of the X-24A are better expressed in the following quotes:

"Flight testing of the X-24A led to one significant accomplishment: the SV-5 shape was the only one evaluated in actual free-flight at hypersonic, supersonic, transonic, and subsonic velocities. Like the M2-F3 and HL-10, the X-24A demonstrated that shuttle-type hypersonic vehicles could make precise landings without power.."13

The X-24B, the last vehicle in NASA's lifting body program was started in 1971 and had more in common with the flat-bottom FDL-7 than previous NASA lifting bodies(M2,HL-10 and X-24A). It is discussed in next sub-section with other LRV programs from 1970s.

With the X-24B, NASA concluded a very successful lifting body program as development of the Space Shuttle began in the early 1970s. The lifting body program contributed significantly to the Shuttle, with vehicle configuration selection in the early design phase and with stability and control during reentry, in the final design. Apart from the technical success, the lifting body program was also successful in using off-theshelf technology for most parts, while developing a new configuration and improving on the vehicle design implementation rapidly. This could be an important lessons for those programs where high-demanding technology was the main cause of failure. It is no surprise that after four decades, the only LRV design currently under development, the SNC Dream Chaser, which is a direct decedent of HL-20 which had its roots in the lifting body program from 1960s. Figure 12 shows vehicle evolution under NASA's lifting body program along with the number of test flights.

\section{The START Program}

The START program was officially defined by the USAF following cancellation of the X-20 program in 1963. It was scheduled to test three lifting body vehicles namely; ASSET, PRIME and PILOT. Of these three, PILOT was merged with the NASA lifting body program as X-24A and is discussed earlier. ASSET and PRIME were precursor to PILOT and were solely under the USAF command with no direct involvement of NASA. 
The ASSET lifting body ${ }^{67}$ had its roots in the late 1950 s when the USAF classified division, the Flight Dynamics Laboratory (FDL) at Wright-Patterson AFB, was given the responsibility for the aerodynamic, performance and aerothermodynamic tasks of the X-20. ${ }^{28}$ The ASSET lifting body was essentially the forward 4 feet of the X-20 glider, developed with the primary goal of supporting the X-20 program in the disciplines of arothermodynamics and structures \& materials development. Instead, by the time ASSET was ready for its first flight in September 1963, the X-20 was already in its final days and was eventually cancelled three months later. ${ }^{22}$ ASSET carried on with extensive ground testing and eventually six test flights under the newly defined START program. Hallion's account of the ASSET and PRIME in "The Hypersonic Revolution - Vol.1"12 is the most comprehensive description of these programs and provides valuable insights into the development process and important contributions. Following excerpts provide some overview of the significance of ASSET:

"ASSET had great application to future systems because it demonstrated the application of refractory materials on hypersonic vehicles; proved that the United States possessed a theoretical base and facility network capable of supporting the aerodynamic and thermodynamic design of such craft; and improved confidence in ground testing and theoretical predictive methods, particularly as involved preventing dynamic and aeroelastic problems on hypersonic vehicle designs....ASSET offered the first practical experience the aerospace community had with an actual lifting reentry vehicle returning from space at near-orbital velocities. Truly it was the pathfinder of lifting reentry...ASSET provided a wealth of data that contributed to the development of more advanced materials (primarily composites and carboncarbon) that would be available when Space Shuttle development began later in the decade." 12

ASSET was followed up by the PRIME, another lifting body configuration developed with a goal to explore the problems of maneuvering entry with emphasis on aerothermodynamics and subsystems discipline. Manufactured by Martin under official designation SV-5D and later referred as X-23, PRIME undertook several ground tests and three test flights that produced wealth of valuable data and technology. A complete list of PRIME's contribution to the hypersonic research body of knowledge is beyond the scope of the current paper. Hallion gives a detailed explanation of specific contributions in trajectory reconstruction, aerodynamics, heat shield and structure, guidance \& control, flap actuation, environmental control, telemetry tracking \& command, instrumentation and electrical subsystems categories. PRIME achieved all its initial objective with such a spectacular success rate that the development team cancelled two further planned launches and the project was concluded. ${ }^{16}$ Rose comments on ASSET and PRIME is fitting to highlight the importance of these programs.

"It would be difficult to overestimate the importance of the ASSET and PRIME tests to the development of the Space Shuttle. "16

\section{FDL Lifting Body Contribution}

The contribution of the Flight Dynamics Laboratory or FDL in the field of hypersonic research is relatively unnoticed, given the important involvement of this organization in major hypersonic programs like X-20, Alpha Draco, NASA Lifting bodies, USAF START, the Space Shuttle, TAVs, BGRV and NASP. Reference [28] identifies the involvement of FDL in the hypersonic research development and comments "...the Flight Dynamics Laboratory has been a major contributor to the understanding of hypersonic flow and pioneered the development of many innovative hypersonic vehicle concepts..."28 While supporting the X-20 program with the ASSET vehicle, FDL was influential in selection of the flat-bottom type shape, which differed significantly from the M2 round bottom body developed via the NASA lifting body program. ${ }^{22}$ This difference in the geometry trend is seen to continue in parallel in both these programs until the X-24B emerges as a converging point, which utilizes X-24A sub-structure with the flat-botteomed FDL-7 outer mold-shape geometry. ${ }^{22}$ Between 1964 and 1968, the USAF contracted Lockheed's Skunk Works to design a Mulitpurpose Re-usable 
Spacecraft(MRS). Lockheed's designs borrowed heavily from the X-20 and eventually evolved into the FDL-5, a flat bottom lifting body based on FDL's prior experience with similar geometry configurations. ${ }^{16}$

The FDL-5 is the only vehicle from the FDL lifting body series which has been assessed by the AHP model in the present context, as it is theoretically one of the best performing lifting body design. The follow-on designs like FDL-7, FDL-8 and McDonnell's seminal model 176 are represented through the $\mathrm{X}-24 \mathrm{~B}$ and $\mathrm{X}-24 \mathrm{C}$ respectively. The importance of the FDL-5 is emphasized via the following quote:

"The configurations chosen for more complete assessment were generally those with the higher aerodynamic performance efficiency as well as geometric compatibility with the payload bay of the space shuttle. One of the more unique configurations developed was the FDL-5 series. The basic problem addressed in this design was to eliminate the fins of the vehicle without degrading the hypersonic $L / D$, the subsonic $L / D$ and the hypersonic directional stability." 28

This effect is shown in Figure 13.

The FDL-5 geometry and design philosophy proved to be a critical design point in the series of lifting body evaluation. It provided much critical insight regarding geometry configuration influences on vehicle's aerothermodynamic and stability performance. The FDL lifting body vehicles were highly classified and not much information is available in the public domain. Rose's remark on FDL-5 confirms

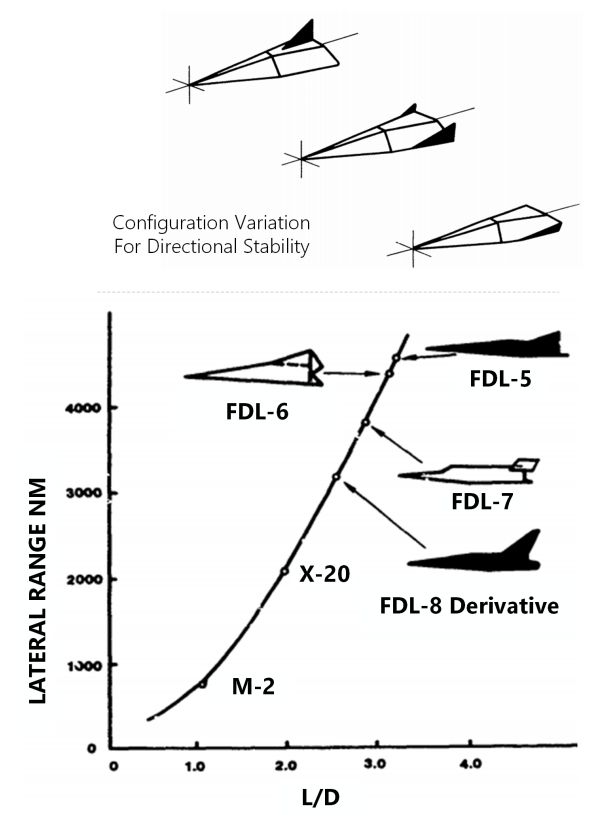
the secrecy:

"Wind tunnel testing of models was undertaken and there have been claims that the mock-up seen in two photographs actually shows a prototype vehicle that was secretly flown between 1969 and 1973. Whether an FDL-5 vehicle was built and tested remains unknown and, officially, the FDL-5 never progressed beyond the mock-up phase.However, the enduring secrecy seems to suggest that a black budget prototype is a distinct possibility." 16

\section{The ILRV Family}

The USAF issued a number of design study contracts under the Integral Launch and Re-entry Vehicle (ILRV) program during 1967-68. The generic systems configuration would consist of a reusable single-stage VTHL RLV with expendable propellant tanks, quite similar to the Space Shuttle final design. Design proposals by Lockheed, General Dynamics, McDonnell-Douglas and FDL were mostly based of the lifting body second stage with differing launcher options for all the concepts. The Lockheed Starclipper utilized the FDL- 5 type flat bottom lifting body as the orbiter stage with wrap-around drop tank. ${ }^{47}$ FDL and McDonnellDouglas also used a flat-bottom lifting body as the orbiter stage while the drop tank implementation was different than Starclipper. ${ }^{68}$ General Dynamic's proposed design, the so-called Triamese was different from the rest in systems configuration implementation as it utilized three identical reusable booster/orbiter element vehicles rather than to develop two different booster and orbiter stages. ${ }^{69}$ No original documentation could be located in the public domain for any of the proposals since the program did not proceed beyond the paper study phase since the proposals were considered too advanced for the time. The similarity with the Space

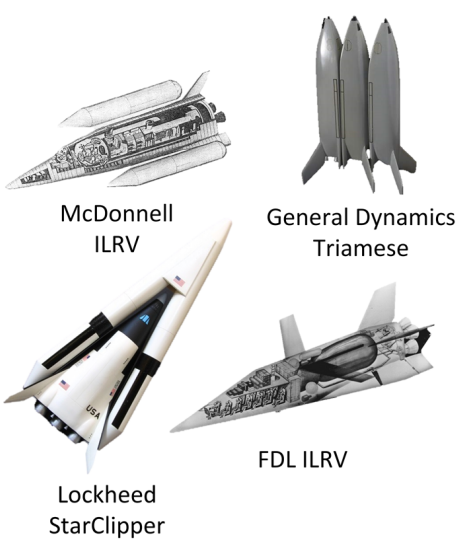
Shuttle in the program requirement suggests a possible influence on the configuration selection as the Shuttle program was initiated just three years later. Figure 14 shows the concepts studied during ILRV program. 


\section{Experimental LRV projects: BGRV and Reentry-F}

In addition to the lifting body evolution, a couple of experimental programs also investigated the hypersonic environment and technology. A follow-on to the 1957 Alpha-Draco, McDonnell's Boost Glide Re-entry Vehicle (BGRV) Model 122E, was developed from the earlier AMaRV missile program to investigate maneuvering at hypersonic speeds after reentry into the atmosphere. The program was highly classified as the bibliography of BGRV official reports in reference [70] classifies all reports as confidential.The following quote eloquently highlights BGRV's contribution:

"served to provide much data on hypersonic maneuvering flight characteristics. This data was of great value in developing later maneuvering re-entry vehicles. Upon re-entry into the Earth's atmosphere, flight control was achieved through the use of the aft trim flares and a reaction jet system commanded from an on-board inertial guidance system instead of by aerodynamic controls." 71

Similar to BGRV, Reentry-F was another experimental test vehicle flown to furnish experimental data on boundary-layer transition and heat transfer during reentry. ${ }^{72}$ The data from this program are still used to benchmark theory and ground test data for the past 20 years. ${ }^{73}$

These two experimental projects mark the end of discussion on the 1960s LRV programs. The evolu-

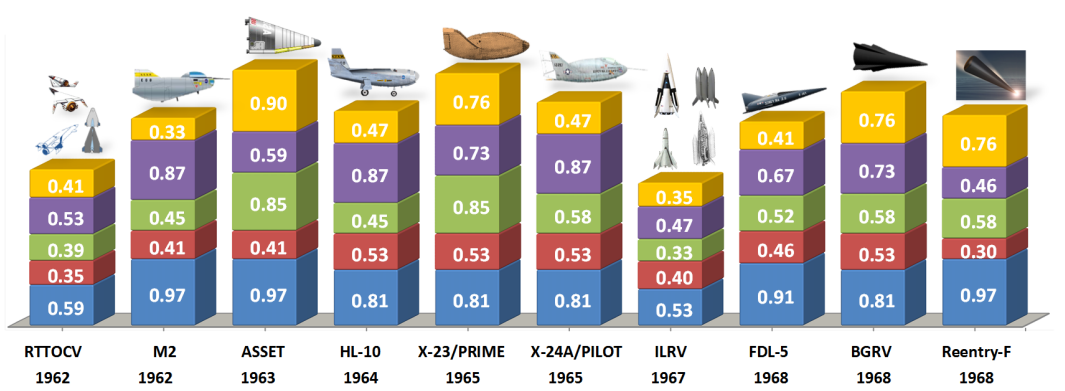

Figure 15: 1960s: AHP Evaluation tion of this era is shown in Figure 10, while the AHP assessment scores are shown in Figure 15. The lifting body development continued under several programs in 1970s along with establishment of the Space Shuttle program.

\section{1970s - The Space Shuttle Decade}

With the success of first moon landing in July of 1969, the US space program was looking forward to a golden era of Space. After five more successful manned moon mission, the Apollo program was terminated in 1972, the same year as the Space Shuttle program was defined. Before discussing the Space Shuttle, the continuation of X-24 program from NASA's lifting body program is addressed with, Figure 16.

\section{Continuing the Lifting Body Development: X-24B and X-24C}

As discussed under the NASA Lifting Body program in the sixties, the development of X-24A began in 1965 within the START program, merging the USAF lifting body efforts with NASA. The X-24A had it's last flight in 1971 leading to its successor, the X-24B. While the previous generation of lifting body at NASA were round bottom designs, X-24B implemented the flat bottom design of FDL-7, a derivative of FDL-5. The X-24B program was developed as a low-speed piloted demonstrator for subsonic, transonic and supersonic testing used in the Space Shuttle. ${ }^{16}$ The program conducted 32 successful flights, gathering important data for performance, handling qualities and stability \& control characteristics. Following quote shows the significance of X-24B:

"The X24B program very successful and produced a of flights in a short time. This was attributed to using and the experienced engineering and flight test team from significant number the $X-24 \mathrm{~A}$ vehicle.. The $X-24 B$ yielded Important information from all phases Of its flight and was the most efficient aerodynamic vehicle of the lifting body series as attested to by the flight test pilots."28

The X-24B marked the end of NASA's lifting body program as the follow on vehicle, the X-24C was undertaken by the USAF alone. While the X-24B was based on the FDL-7, X-24C was an air-breather implementation of the FDL-8 lineage. ${ }^{16}$ Several configurations of X-24C were explored by the FDL with scramjet and rocket powered versions, with the main goal to develop a new hypersonic scramjet-flight demonstrator 
reaching speeds upto Mach 8 . Although the X-24C was cancelled due to tight budget constraints and the inability to identify a pressing nearterm need for the flight facility, it is still considered as a significant milestone-effort to combine scramjet propulsion with a lifting body design, overall producing important data during the ground tests. Hallion's quote below is addressing the value of the X-24C experimental data:

"Eventually, X24C gained the distinction Of being the most extensively studied and analyzed "nonflown" hypersonic vehicle."13

The X-24C program was also considered for a proposed hypersonic testbed, the National Hypersonic Flight Research Facility (NHFRF), a vehicle that could have modular-type experiments for materials and various forms of propulsion, including scramjet test modules, implementing hypersonic cruising. The NHFRF program showed promise as several agencies expressed their interest in a next generation demonstrator, but failed to win support and was cancelled in late 1970's after one test-flight. ${ }^{74}$ The X-24C marked the end of the lifting body effort in the 1970s as the Space Shuttle took center stage.

\section{The Space Shuttle Program Definition}

The space Shuttle program was officially initiated in 1972 as the development continued for the rest of the decade with conributions from almost all major aerospace manufacturers. The Space Shuttle represents a converging and pivot-point for the lessons learned and technical progress made in the previous programs towards the first generation of an operational partially reusable LRV. Important contributions were made by the Shuttle in all the disciplinary criteria which are still used as a benchmark, particularly in the fields of rocket propulsion with SSME and thermal management with its tiles-based TPS. ${ }^{61}$ The Shuttle is scored highly in all the discipline area as it was the first operational LRV program that implemented latest technology and paved a path towards the future generation of LRVs. The success of the program is an issue of debate, as the main objective while defining the program was to develop a reusable SAS that could provide a much less-expensive means of access to space. ${ }^{75}$ Subsequently, this primary program requirement was not satisfied, as the Shuttle turned out to be much more expensive compared to the original hopeful estimates. ${ }^{76}$ The Shuttle program was retired in 2011, after 133 successful missions and two failures of the Challenger at the launch and the Columbia during the re-entry phases. Even though the Shuttle was not a commercial success, it was the most advanced piece of technical ingenuity that played a key role
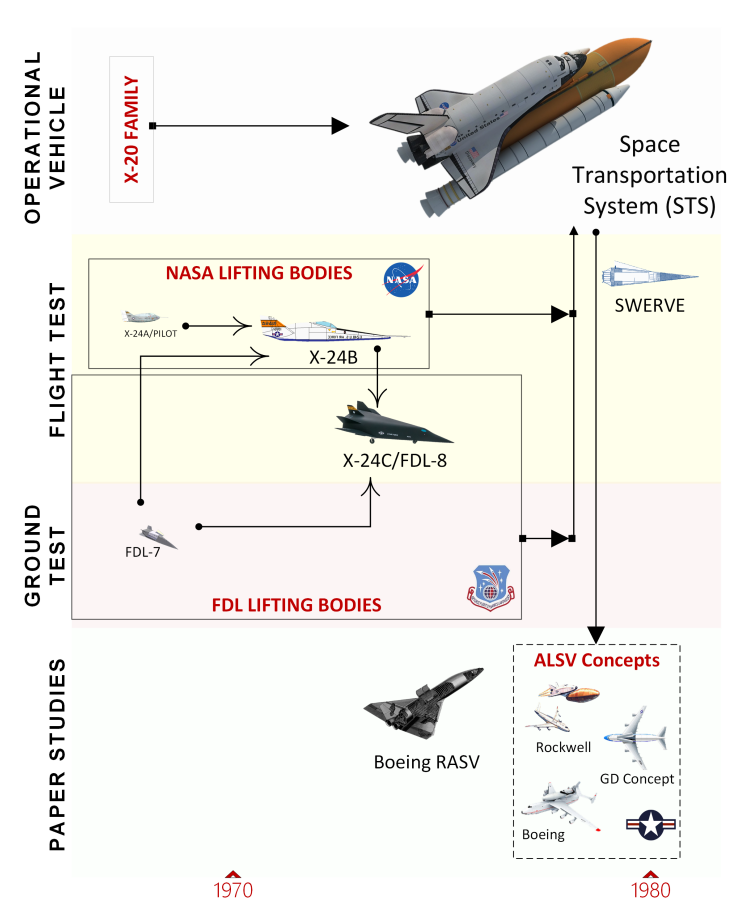

Figure 16: 1970s: LRV Evolution in assembling the ISS, the Hubble telescope and served as the primary means of man-rated space access for the United States for almost three decades. It is by far the most documented LRV program; further specific details of its main contributions can be found in reference $[77]$.

\section{Other LRV Efforts}

Several other LRV programs were initiated by various institutions in the second half of the seventies, to further extend the capabilities of next generation SAS by utilizing the Shuttle as the starting point. ${ }^{20}$ A 1976 Boeing initiative, the RASV program represents another such failed attempt. The company's interest in the reusable single-stage-to-orbit (SSTO) vehicle was "..based on the belief that the reusable airplane type operation of earth orbit transportation vehicles will allow considerable improvement in cost per flight and flexibility."78 The program was cancelled after the paper study phase when the USAF started to focus its 
attention on the X-30 NASP. For further details on the RASV program, readers are advised to refer Dick and Launius. ${ }^{20}$

The USAF continued with the research on small spaceplane designs with the largely classified Air Launched Sortie Vehicle (ALSV) program, ${ }^{16}$ another precursor to the X-30. Proposals were submitted by Boeing, Rockwell and General Dynamics for the ALSV, which resembled Shuttle's configuration of a reusable LRV glider with expendable fuel tanks, but were launched by a modified aircraft as the first stage. There is little information available regarding individual proposals which hints that the program did not progress beyond paper studies, as the performance of the ALSV was not particularly impressive, while the technical challenges were daunting. ${ }^{79}$

Following the lineage of experimental programs from the sixties, the SWERVE program was a maneuvering reentry body based on a slender cone configuration, with small wings and elevons. ${ }^{80}$ Similar to the BGRV and Alpha-Draco programs, SWERVE provided much of the aerodynamic and aerothermodynamic experimental data from three test flights beginning in $1979 .{ }^{81}$ Hallion recognizes the importance of these experimental vehicles in following quotes;

"...the greatest contribution of programs such as the BGRV, Reentry-F, SWERVE, and FIRE (and, for that matter, the X-15 and even Shuttle later) was in highlighting the often great differences between predicted and actual performance, and the great need for more accurate ground test facilities, simulation techniques, and predictive tools..." 8

The AHP assessment and the evolution of the 1970s LRV programs is shown in Figure 17.

\section{The LRV programs of $1980 \mathrm{~s}$}

Two case-studies from the 1980s are considered as major contribution towards the LRV evolution. First program was similar to the ALSV and ILRV programs of the previous decade, as the USAF “..initiated a technology exploration program to examine small and easily maintained rocket-powered air-andground launched advanced hypersonic systems..." 8 . This group of concepts called Trans-Atmospheric Vehicles $(\mathrm{TAV})^{82}$ were reminiscent of concepts proposed in the late 1960s and the early 1970s for the Shuttle program. The TAVs were envisioned as a new type of reusable launch vehicle with much broader

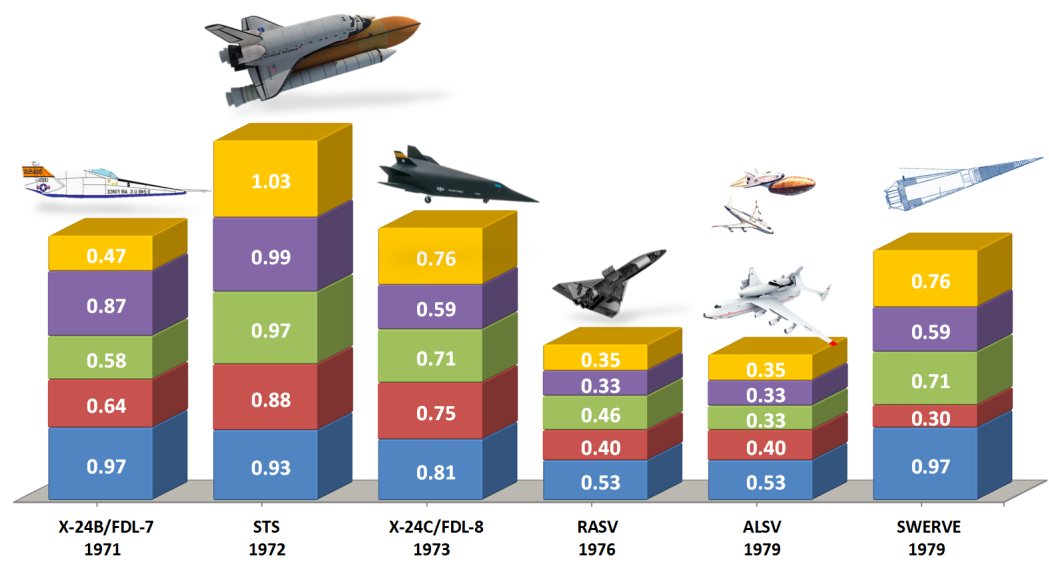
operational capabilities, and application towards multiple mission categories. ${ }^{83}$ The following quote by Rose support this notion further:

"It could take-off from normal runways as a conventional aircraft, it could be boosted on a suborbital flight using a Shuttle Solid Rocket Booster (SRB), or the TAV might be carried into orbit within the Shuttles payload bay. It was to be powered by one large rocket engine and two turbojets with options to reconfigure the propulsive system for different missions." 16

A workshop held at RAND to examine the TAV's mission, technical and design feasibility issues had the following remarks:

“..Discussions at the workshop and subsequent investigations reveal that despite the efforts of past programs, significant technology challenges remain, especially in the areas of propulsion, thermal protection systems, and overall vehicle integration... ${ }^{83 "}$ 
Another important LRV program from 1980s is the HL-20 lifting body envisioned as a Personnel Launch System(PLS) and later as a Crew Emergency Return Vehicle(CERV) to provide manned crew return complementing the Space Shuttle. ${ }^{84}$ The vehicle was inspired by the Soviet BOR-4 lifting body, a test vehicle under the Soviet Shuttle program, the Energia Buran. ${ }^{16}$ The NASA Langley personnel who worked on the 1960's lifting body program were also involved in the HL-20 development. the HL-20 conducted numerous aerodynamics investigations to improve low-speed characteristics of the vehicle to enable a horizontal runway landing. Further ground tests were conducted leading to a full-size mock-up model of the vehicle that furnished valuable data. ${ }^{85}$ The following quotes form NASA confirms the value of the HL-20 research effort:

"..A significant amount of research effort has gone into experimental and computational investigations of the baseline HL-20 shape. The goal has been to amass a data base of information about this system to aid in management decisions for PLS development..." 86

Although the HL-20 was could not progress beyond the ground testing phase during the early '90s, it became the basis of the 2005 Dream Chaser vehicle. This design is the only active LRV design to reach orbital capability is currently under development by the Sierra Nevada Corporation. Chiara has addressed the evolution of Dream Chaser from the HL-20 in reference [87] that was acquired by the author from Chiara himself and is available on the internet, but is not published officially in a journal or conference yet. The AHP assessment results and the evolution of the TAV and the HL-20 program included within the 1990s LRV case-studies are discussed next.

\section{E. 1990s: Reusable Launch Vehicles}

The nineties started with the continuation of the HL-20 under the CERV program and showed a revived interest in the LRV design. A series of technology-demonstrator programs initiated by NASA in 1995 included the X-38 for the CRV, followed by the X-33 demonstrator for Lockheed Venturestar concept, and finally ended at the closure of the decade with the definition of the highly secretive $\mathrm{X}-37$ program. But before these demonstrators, another concept that addressed the LRV design in the first half of the decade was a private initiative by the Pioneer Rocketplane, is discussed first.

\section{The Pioneer-Rocketplane Pathfinder Family}

Pioneer Rocketplane ${ }^{88}$ proposed concept for the Black Horse vehicle in 1993. The design was a match for the USAF TAV requirements, leading to paper studies at the USAF Phillips Laboratory. The initial design was further improved in the follow-up concept, the Black Colt, a one-crew SSTO launch vehicle powered by turbofan and rocket engines. ${ }^{89}$ "...Subsequent to the TAV workshop, RAND performed an independent analysis of Black Horse's payload capability and found it could not reach orbit... ${ }^{83}$ " The concept design from Black Horse and Black Colt was further refined with the Pathfinder Rocketplane design in 2001, but could not evolve beyond paper studies phase.

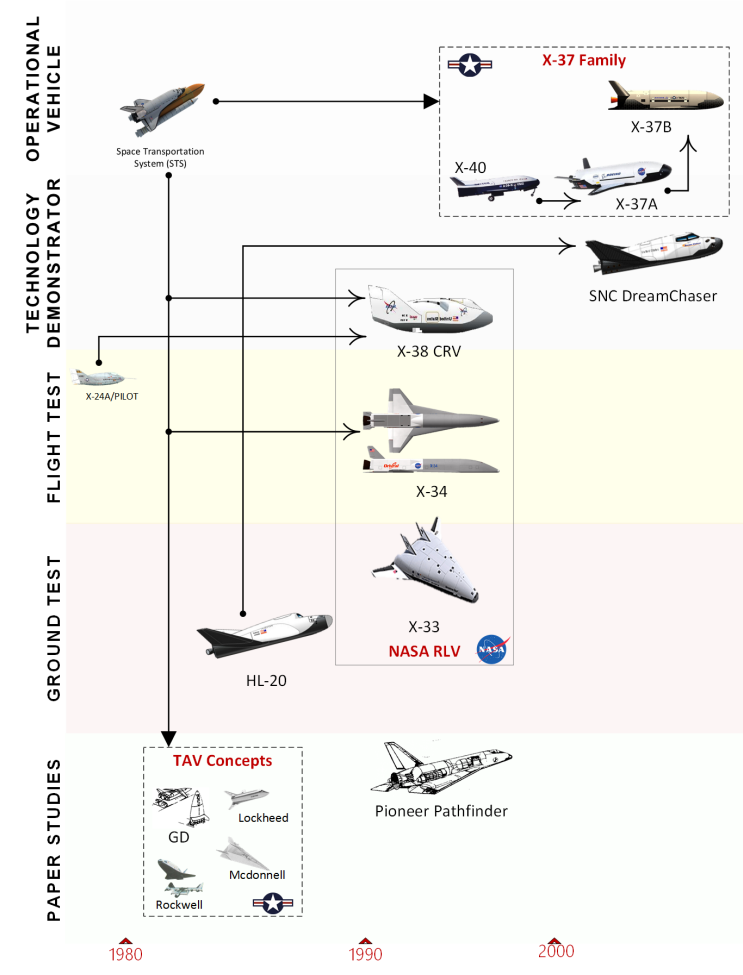

Figure 18: 1980s Onwards: LRV Evolution

\section{NASA Reusable Launch Vehicle Efforts}

Sometimes around 1994, the NASA Reusable Launch Vehicle (RLV) program was initiated, that resulted in four 'X-series' spaceplanes namely the: X-33 and X-34 under Reusable Launch Vehicle Program, and the $\mathrm{X}-38$ for the CRV and the $\mathrm{X}-37$ for the OTV program. ${ }^{90}$ 
The X-33 program was initiated as a part of the RLV program in 1995 as a testbed for developing technologies for an integrated RLV design, paving the way for full-scale advanced commercial launch system, ${ }^{91}$ see Figure 19. Lockheed Martin offered a VTHL lifting body concept based on the aeroballistic rocket, the VentureStar, and was selected by NASA against proposals by McDonnell-Douglas and Rockwell. ${ }^{90}$ The Venturestar proposed to use a linear aerospike engine, metallic insulation, and several other features similar to their Starclipper proposal. $^{92}$ Lockheed developed the X-33 as a technology demonstrator for the Venturestar concept and employed composite materials to reduce vehicle weight. This was one of the key requirements to successfully develop the Venturestar. However, the composite fuel tank failed during a testing in 1999 and it was concluded that composite technology was not mature enough at the time for such use in cryogenic reusable tanks. ${ }^{93}$ This proved to be a fatal blow for the X-33 as program ran into cost and schedule overrun and was finally cancelled in 2001. The main lesson learned from X-33 was that the program accepted multiple technology risks, overall resulting in program failure. Related to the cryogenic composite tank and other aspects, the X-33 proved to be of significant value for the structure and materials discipline.

The next vehicle under the RLV program was the Space Shuttle-inspired X-34 technology testbed, ${ }^{94}$ a development by Orbital Sciences Corporation in 1996. It was planned to be an autonomuos vehicle, powered by a completely new reusable Fastrac engine, capable of reaching Mach 8 and performing 25 test flights per year. ${ }^{90}$ The X-34 program too ran into cost and schedule overrun, similar to the X-33 as two unpowered flight test-vehicles were built spending just under $\$ 112$ million before the program was cancelled in 2001 with the X-33. The following quotes by Sullivan show the main disciplinary contribution from the X-34 program:

".. The technological developments included autonomous ascent, reentry, and landing; composite structures; reusable liquid-oxygen tanks; rapid vehicle turnaround; and a durable TPS. The versatile flight testbed could accommodate future experiments, including space transportation and technology developments and aeroscience experiments..."95

Following the cancellation of the HL-20, NASA began developing X-24A derived X-38 research vehicle aimed at the development of technologies for a prototype emergency crew return vehicle(CERV). NASA was supported by the European Space Agency(ESA) through the DLR TETRA project for a common concept vehicle to satisfy their Space Station crew transport needs. ${ }^{96}$ The program developed three test prototype vehicles conducting several autonomous test flights (horizontal parafoil runway landings) and tested technologies, for disciplines such as aerodynamics/aerothermodynamics, structures, TPS and flight control systems. European contribution to the X-38 program was found in all technical areas as the X-38 established first transatlantic venture for development of a reusable spaceplane. ${ }^{97}$ The X-38 was eventually cancelled in 2002 due to budget cuts and could not result in an operational vehicle, but proved to be valuable for testing new structures and TPS materials improving aerothermodynamics database. Further details on the contributions by X-38 can be found in reference [98] and [99] .

The X-37 program evolved out of the Boeing X-40 demonstrator for the USAF Space Maneuver Vehicle(SMV) under the Military Spaceplane Architecture program. ${ }^{6}$ The first generation vehicle of the program was the X-37A Approach and Landing Test Vehicle (ALTV) and was used in drop glide tests in 2005-2006 by NASA. ${ }^{100}$ The second generation Orbital Test Vehicle(OTV) or the X-37B, was developed and operated independently by the USAF and is currently operational, but remains highly classified regarding the details of mission details. The following quote by Grantz adequately represent the key technology and disciplinary contribution by the $\mathrm{X}-37$ program:

“...Several key technologies for reusable spacecraft were successfully demonstrated in the areas of aerodynamics, aerothermodynamics, reusable solar arrays, Thermal Protection Systems (TPS) and autonomous Guidance, Navigation, and Control (GNC). The current system provides a 
demonstration platform for autonomous spacecraft technologies, on-orbit environments for material and microelectronic characterization and re-entry environments for advanced TPS materials and concepts..."101

$\mathrm{X}-37$ was the last LRV program initiated in the nineties and is the only LRV vehicle currently operational. The 1990s were a tough period for LRV programs where many bold initiatives were undertaken to establish a reusable SAS, but only the X-37 evolved to an operational vehicle status. The lessons learned were expensive and difficult but contributed immensely to hypersonic knowledge evolution. The evolution for the LRV program from 1980 onwards is shown in Figure 18

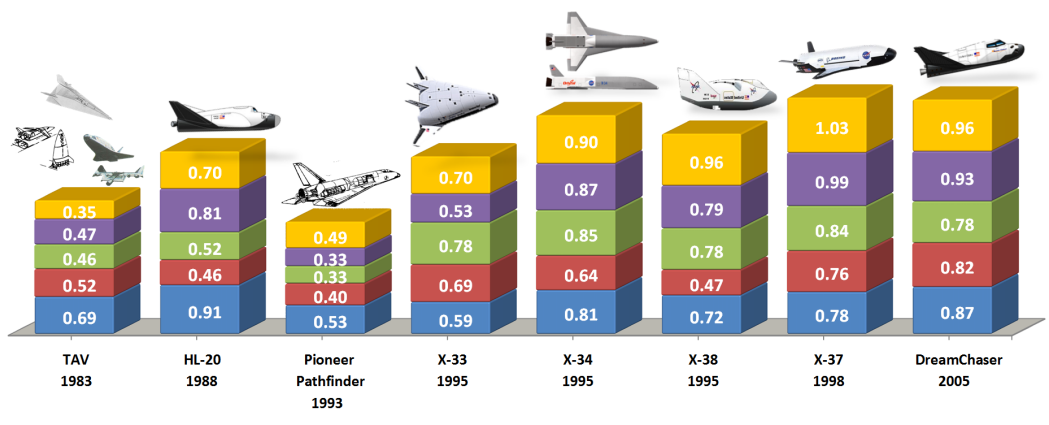
and the AHP results for these casestudies are given in Figure 20 that includes the last case-study, the Dream Chaser, which is discussed next.

\section{F. Post 2000: The Dream Chaser}

The last US-based LRV case-study considered for this survey is the 2005 private initiative, SpaceDev's HL-20 inspired lifting body vehicle, the Dream Chaser. ${ }^{102}$ The Sierra Nevada Corporation(SNC) acquired SpaceDev and took over the Dream Chaser vehicle in 2008. Two years later, Dream Chaser was selected for NASA's Commercial Crew Development (CCDev) Phase-1 program, as SNC continued with the ground tests, and further modified the design supported by funding and with technical cooperation from NASA. ${ }^{103}$ The Dream Chaser was eventually dropped form the CCDev contract in the last seletion round and later selected under NASA's Commercial Resupply Vehicle program for a conract of six resupply missions to the ISS. ${ }^{104}$ It is expected to be operational by 2018, delivering cargo and science experiments for NASA as the primary mission, although SNC is developing multiple variants for international customers as well. ${ }^{105}$ The vehicle is developing and employing state-of-art technology in most subsystems, ${ }^{106-109}$ while building on the crucial aerodynamics knowledge base gained via the legacy HL-20 program. The AHP analysis results for the Dream Chaser is given in Figure 20 with rest of the LRV programs form 1980.

A combined LRV evolution of the US-based case-studies is shown in Figure 21 summing up the discussion of the US LRV history. Tracking the evolution through these historical programs helps to visualize, how the current Dream Chaser utilizes the hypersonic knowledge gained with incremental gains in individual program. The following section addresses the AHP assessment of the LRV efforts outside the US with a brief overview of major programs.

\section{International LRV Case-Studies Assessment: Silvervogel - IXV}

Outside the United States, numerous LRV programs have been undertaken by several European and Asian countries. A total of 29 LRV case-studies from USSR/Russia, ESA, Great Britain, Germany and Japan have been assessed by the AHP model. In the following subsections, ESA, Germany, and Britain are discussed collectively under the European LRV programs, followed by a brief discussion of LRV programs in Japan and finally, Soviet/Russia.

\section{A. European LRV Efforts}

Several lifting reentry programs were initiated during the early 1960s in Germany and Britain, ${ }^{29}$ while post 1980s, ESA undertook several LRV-based research projects and technology development programs. The evolution of these European LRV case-studies is visualized in Figure 22 and described in the further details as follows. 


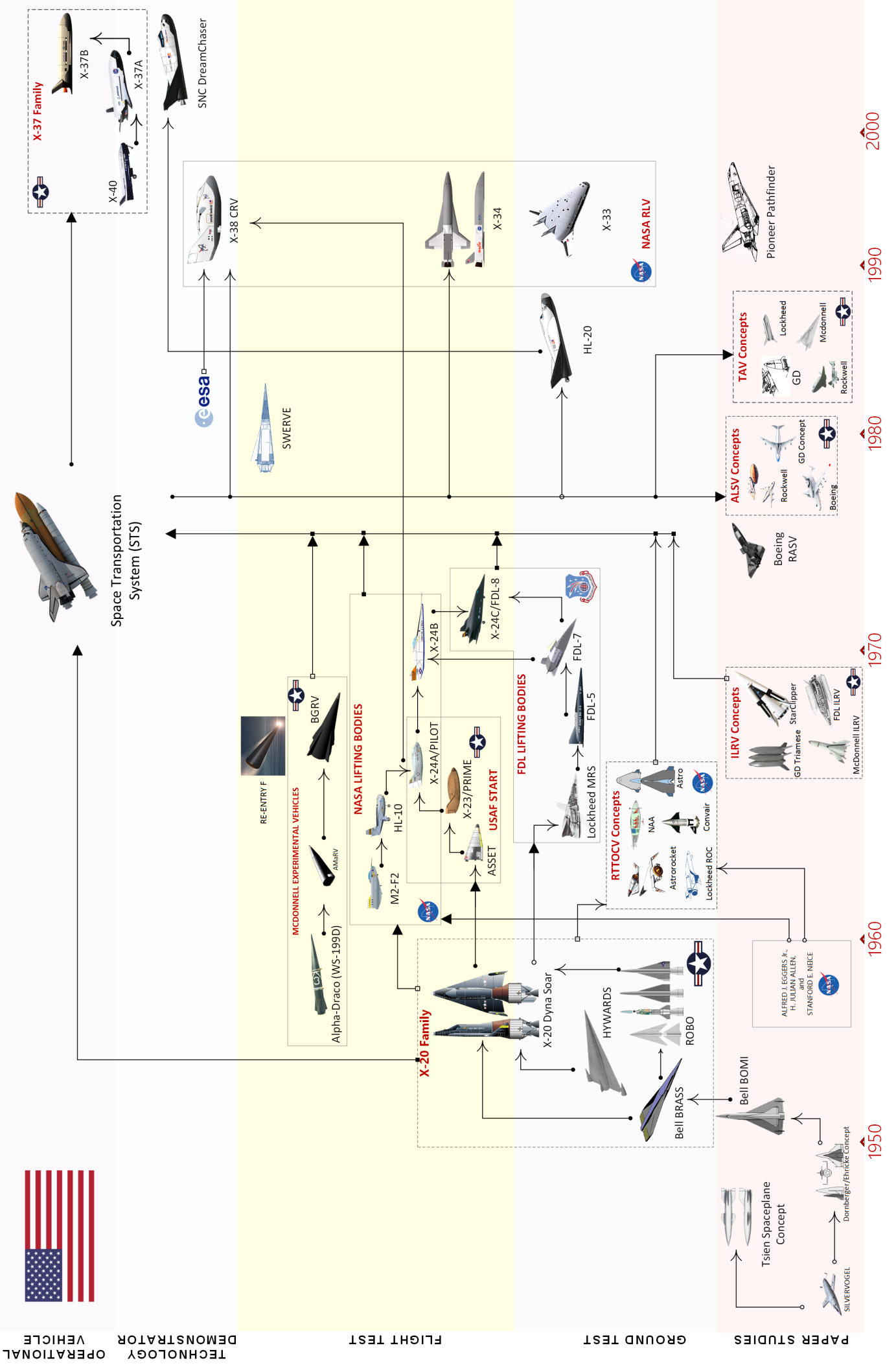

Figure 21: US-based LRV Programs Evolution 


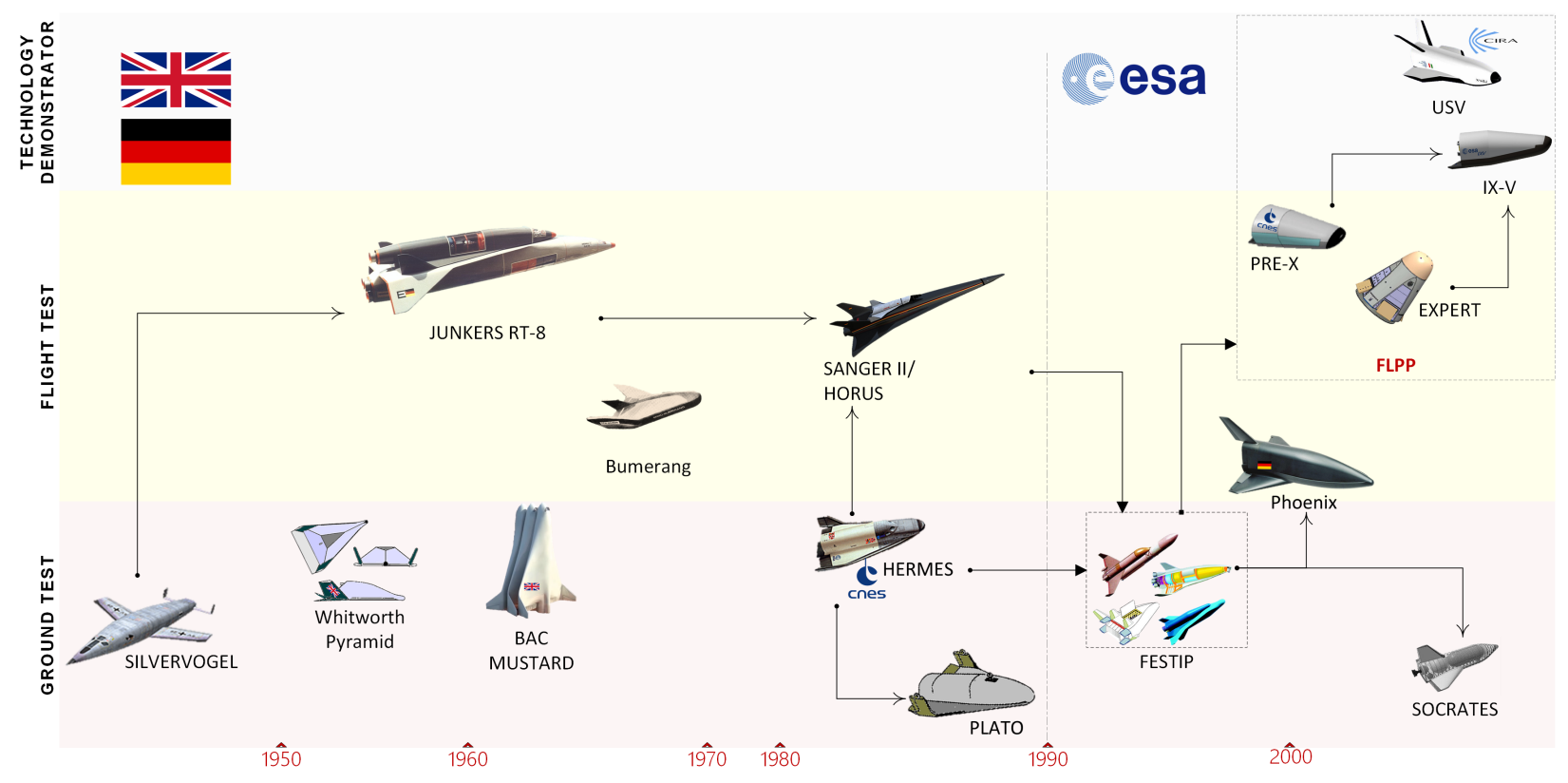

Figure 22: European LRV Programs Evolution

\section{The German LRV Programs}

The concept of hypersonic LRVs dates back to as early as the 1930s, when Eugen Sänger in 1933 Germany, proposed the concept for Silberbogel(German for SilverBird) rocket plane. This was a definitive study, establishing the feasibility of rocket propulsion with airplane-like lifting configuration. Eugen was assisted by his future wife, Irene-Bredt, in further refining the design details in the later half of the decade. The vehicle was a rocket-propelled winged airframe, running on liquid oxygen and kerosene. It was proposed to be launched from a rocket-boosted sled to perform sub-orbital missions, reaching altitude of 100 miles, and achieving hypersonic speeds in order of Mach 10 during the reentry. ${ }^{110}$ The Silvervogel concept underwent several wind tunnel and propulsion system tests by 1942 improving on the conceptual design studies. It was later found that vehicle would have generated unacceptable levels of airframe heating due to the skipglide trajectory implementationa nd the low wing sweep angle, as this important issue had not been fully appreciated by Sänger and Bredt, and would have led to insurmountable problems if their project had gone forward. ${ }^{16}$ The design concept was considered by Nazi Germany to be developed into the Raketenbomber or 'rocket bomber', but never evolved beyond ground tests until 1963 as Junkers RT-8-01. Further details on the Silverbird and the follow-on designs can be found in reference [111], [1] and [112], authored by Eugen and Irene Sänger.

Between 1961 and 1964, Eugen Sänger was working with JUNKERS FLUG-ZEUG UND MOTORENWERKE (JFM) company in Munich on the Silvervogel follow-on design studies, for a sled-launched two stage space-plane system, the Junkers RT-8. Both, the first and second stages were delta-winged LRV designs, equipped with LOX/LH2 engines. The upper stage was a reversed version of the first stage launch vehicle, with the low-mounted wing, having upturned tips like that of the X-20 Dyna-Soar, and would be able to reach 300km altitude orbit. ${ }^{47}$ Sänger was working on the RT- 8 until the morning of his sudden death in February 1964. The design went through several iterations under Messerschmidt-Boelkow-Bloehm (MBB) as RT-8-02, but was eventually dropped in 1969. Eugene Sänger's work towards the LRV concept is undeniably the most influential contribution by an individual. He applied the rocket science fundamentals developed by Esnault-Pelterie, Goddard, Oberth and Tsiolkowski, into a practical concept, based on the philosophy of the so-called "school of Vienna", where Valier, Vonhoefft and Von Pirquet imagined aircraft capable of reaching orbital velocities. ${ }^{113}$ Sänger's life was dedicated to the idea of realizing a rocket-plane to access space. A detailed account of his work is documented by his son Hartmut Sänger, ${ }^{113}$ who describes the importance of Sänger's legacy in these words:

"Eugen Sänger, however, was one of these rare, gifted engineer-physicists whose deep understand- 
ing of a technical knowledge which he partly created, combined with a real talent for large-scale project management, could turn some of these dreams into reality and, as such, help astronautics break the science-fiction barrier." 113

Another major German LRV concept in the 1960s was the lifting body design, Bumerang. Developed by ERNO through a series of wind tunnel tests followed by unpowered flight tests, the Bumerang followed the contemporary NASA Lifting Body program and contributed to the Space Shuttle's project-definition phase with McDonnell Douglas. ${ }^{114}$ Major contributions made by the Bumerang were in the disciplines of aerothermodynamics, thermal management, and sub-systems as found in the detailed description in reference [115] and [116].

In 1985, MBB began renewed studies of the Sänger spaceplane, this time, a two-stage-to-orbit horizontal takeoff concept. The first stage was a turboramjet powered delta-wing design, for boosting the orbiter vehicle called HORUS, which was based on the CNES Hermes vehicle. ${ }^{117}$ The program was the reference concept of the German Hypersonics Technology Program and achieved major results in disciplines of propulsion, structures \& material, subsystems and aerothermodynamics. ${ }^{118}$ However, the propulsion research was mainly concentrated on air-breathing launch stage, which proved unsuccessful in developing a feasible propulsion system and the program was terminated in 1995 due to budget cuts. Sänger II concept was also studied under the FESTIP program by ESA and further details of the vehicle system and major contributions are found in references [118] and [35].

In 1987, ERNO and MBB started working on a winged LRV design called The Platform Orbiter or PLATO for short. The program emerged out of Europe's desire to not be dependent on the US Space Shuttle for orbital access, as PLATO was planned to be launched by European Ariane 4 rocket from Kourou, French Guiana, and land horizontally in southern Europe. ${ }^{119}$ Several wind tunnel activities and trajectory simulation models were developed for PLATO. However, the program could not develop beyond these ground tests and was cancelled in 1990. References [120] and [121] are some of the best sources found for this project, describing the research effort development under the program.

PLATO concludes the discussion of LRV programs initiated in Germany. Figure 23 shows the AHP results of the Germany LRV programs along with the British concepts, Whitworth Pyramid and BAC MUSTARD, which are discussed next.

\section{The British LRV programs}

Two British programs are seen to fit the LRV class and are analyzed here in the AHP model. The first study originated in 1954, an unusual pyramid-shaped design with a flat underside and short wings, was developed by Nonweiler following the development of his famous wave rider concept. Rose ${ }^{16}$ provides further details for this design development, which suggests the vehicle made developments in aerothermodynamics and subsystems disciplines through a series of wind tunnel tests, leading to various design modifications. The vehicle could not evolve beyond that stage and was cancelled in 1960. During this period, the British Aircraft Corporation (BAC) was conducting studies for developing a small British spacecraft using delta-winged designs. Following on its initial hypersonic and spaceplane studies, the BAC began work on the government funded studies aimed to develop a reusable manned Orbital Transporter. Inspired by the American lifting body design and the modular concept as implemented in the McDonnell Astro and Convair Triamese, program MUSTARD was defined in 1962. The vehicle configuration resembled closely the Convair Triamese design using three identical lifting-body stages. Although no technical report has been available for MUSTARD, several FLIGHT magazine articles 
and two patents filed by BAC ${ }^{122,123}$ in 1969, reflect that MUSTARD developed ground-test articles and made significant progress in propulsion and aerothermodynamics disciplines. ${ }^{124}$ The AHP results for these two programs are given in Figure 23 with German programs.

\section{LRV programs from ESA}

The European Space Agency (ESA) was established in 1973 following the reforms made to previous European space collaboration under ESRO and ELDO. ${ }^{125}$ The LRV case-studies evaluated for ESA represent a collective effort of several European national space agencies from the 1980s onwards, starting with the French program, Hermes.

The first LRV case study considered as a joint ESA project is the 1985 Hermes program, originated in the second half of the 1970s within the French Space Agency CNES. ${ }^{126}$ Inspired by the US Space Shuttle and the X-20 programs, ${ }^{16,127}$ the project started with the basic idea of realizing a small manned space plane was a winged reusable re-entry vehicle to be launched on top of the European Ariane-4 launcher. Its sole original purpose was the transport of two to four astronauts into low Earth orbit (LEO) as a kind of 'space taxi' for autonomous missions. However, since the beginning of the program, the need for a European manned space capability was not clearly specified as the basic requirements and underlying specifications were changed more or less continuously. The focus of the program shifted from an operational space transportation system towards a manned experimental space vehicle and finally a pure technology demonstrator before being cancelled in 1992 owing to the mass budget complications. ${ }^{127}$ Bayer further elaborates; "..After years of development of Ariane 5 and Hermes, the most basic requirement of the compatibility of the payload mass with the launcher had still not been achieved despite the fact that the transport of Hermes was one of the primary design missions of Ariane 5. In general the configuration chosen for Hermes was not adequate for the multiple demands posed on it, and the absolute size of the vehicle was too small for the required functions..." 127 Although the program could not develop a feasible SAS, a considerable amount of technology-specific research was conducted while the program was active, especially in the disciplines of aerothermodynamics, thermal management and subsystems development. ${ }^{117,128-130}$ The Hermes configuration show uncanny similarity with the X-20 program as both programs shared similar mission requirements, design configurations and were cancelled due to similar reasons. The program was a crucial learning curve for the ESA partners and has been studied and documented extensively for major lessons learned in organizational, programmatic and technical aspects. ${ }^{127,128}$

Utilizing the lessons learned from the Hermes experience, ESA decided to perform a detailed concept investigations on a commonly agreed basis among the participating nations, with closely related technology preparation under FESTIP. The primary objective was stated as: "..FESTIP will enable Europe to take decisions on the development of a next generation launcher." 131 The FESTIP program was defined in 1994, comprising a system study as the focal point, and five technology studies in the key technology areas. ${ }^{132}$ Readers are reminded that the five disciplinary criteria selected for the AHP model implemented in this study were borrowed from FESTIP's definition. The FESTIP program played a key role in defining common goals among participating agencies to provided a path for maturity of key technologies. ${ }^{133,134}$ Several vehicle concepts were analyzed

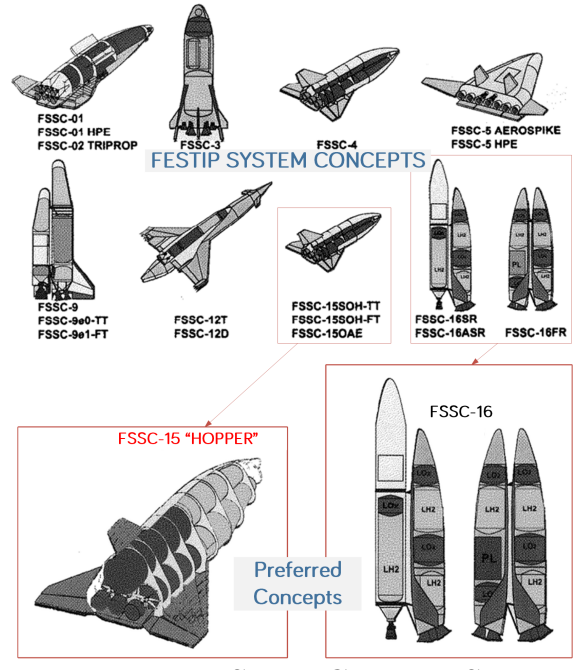

Figure 24: FESTIP Concept Studies and Final Selection during the initial configuration selection phases as shown in Figure 24. Following the initial evaluation, concepts FSSC-15 and FSSC-16 were preferred on the basis of technical feasibility and economic viability. ${ }^{49}$ Technical feasibility and mission performance were claimed to be achieved by all concepts and further details on individual system concepts can be found in references [135] and $[136]$.

In 1998, the FESTIP team selected FSSC-15 HOPPER as the final concept and decided to pursue detailed design work within planned Future Launcher Technology Programme(FLTP), foreseen for 19992005. Based on the configuration of the HOPPER concept, the German ASTRA program started developing the Phoenix test vehicle as the EXTV option for FESTIP. ${ }^{137}$ The main objective was to demonstrate fully autonomous approach and landing for an RLV-like configuration, possessing relatively poor low-speed flying 
qualities. ${ }^{6}$ In 2004, the vehicle executed the only drop-test flight, executing a fully autonomous landing. A part of the FLTP objectives was to develop and validate the required technologies for the HOPPER vehicle. But unbalanced participation in the program by various member states and the consequent problems with implementing procedures resulted in the FLTP being put on hold, ${ }^{138}$ and eventually canceled, along with the suborbital HOPPER concept and its sub-scale test-bed vehicle, the Phoenix. Another testbed vehicle based on the Hopper's configuration was the SOCRATES program with goals to demonstrate most RLV mission phases, from autonomous takeoff to abort capabilities. ${ }^{6}$ Apart from the major objectives and initial program definition requirements, not much information is found on this proposed testbed, now assumed to be abandoned after the cancellation of Hopper.

Following the FTLP debacle, the Future Launchers Preparatory Programme(FLPP) was initiated in 2004 to prepare the next generation of launchers, starting with system studies carried out under FESTIP. During the next phase of the program, FLPP initiated ".. a progression of test vehicles to explore the physics of, and demonstrate the capability to accomplish, controlled reentry flight.. ${ }^{139}$. The first of these programs was the European eXPEriment Reentry Testbed(EXPERT), intended to gather data on reentry aerothermodynamic phenomena using a geometrically simple, but highly instrumented non-maneuvering reentry vehicle." 6 EXPERT was supported by several aerothermodynamics facilities throughout Europe, equipped with 14 experiments provided by several scientific institutions all around Europe. ${ }^{140,141}$ EXPERT performed several flight tests as a precursor to the IXV technical demonstrator, providing important data for aerothermodynamics and thermal management disciplines.

Another program leading to the FLPP IXV began in late 2000 when the French space agency, CNES, began with preliminary assessments of a lifting testbed called the Pre-X. The main objectives were defined to develop and demonstrate technologies in thermal management, aerothermodynamics, and subsystems disciplines. ${ }^{142}$ Following the initial preliminary design period, Pre-X has undergone extensive detailed design analysis and ground testings to develop the vehicle, in order to comply with in-flight experiments plans. ${ }^{143,144}$ The Pre-X configuration became the basis of the FLPP-IXV demonstrator.

A significant LRV effort under the FLPP initiative was the CIRA (Italian Aerospace Research Center) program, PRORA-USV, "to develop and flight test technologies critical to future-generation reusable launch systems." ${ }^{6}$ The vehicle conducted technology demonstration flights providing a valuable system and subsystem feasibility insight. Ruso ${ }^{145,146}$ provides further details of the program's main objectives and major contributions to the disciplines of subsystem and structures. These trends are also seen in

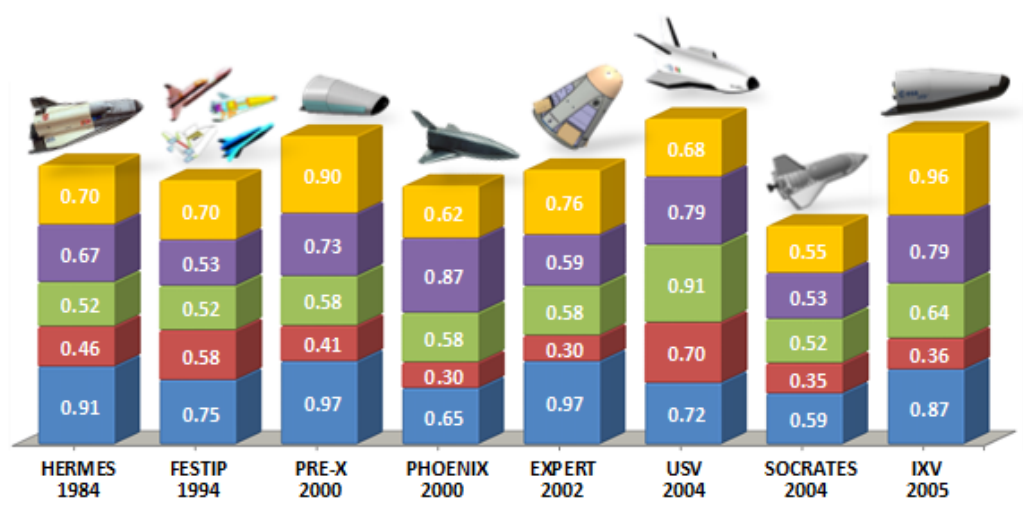

Figure 25: ESA LRV Programs: AHP Evaluation the AHP results.

During the Period-1 stage of the FLPP program, the industrial systems team was tasked to select the most promising ongoing studies for the Intermediate Experimental Vehicle (IXV). As mentioned earlier, CNES Pre-X was selected as the optimum design and the IXV adopted the external configuration of the Pre-X. ${ }^{147}$ Multiple goals identified for the IXV were: “..demonstrate hypersonic unpowered maneuvering reentry flight of a lifting configuration, serve as a test-bed for in-flight qualification of vehicle subsystems and systems, and to provide another source of data on fundamental hypersonic aerothermodynamic phenomena for validation of tools, databases, and design processes.." ${ }^{6}$ With these goals, the IXV was to develop on the in-flight research conducted by the EXPERT program. ${ }^{148}$ The IXV flew on its successful maiden test flight in 2015, producing important aerodynamics and thermal data. The program is scored high on aerothermodynamics, thermal management, and subsystems disciplines and is planned for the follow-up flights in 2019/2020. ${ }^{149}$ The IXV is the last case-study considered for the ESA-initiated LRV efforts, most of which saw fruition as technology demonstrators for the next-generation reusable launch vehicle. The AHP results for the ESA case studies are shown in Figure 25. 


\section{B. LRV Efforts in Japan}

The LRV research efforts in Japan are focussed under the HOPE(The H-2 Orbiting Plane) program started in the 1980s by NASDA and NAL (both now part of JAXA). Following the early paper studies, the development plans led to the HOPE$\mathrm{X}$, a full-scale demonstrator for the operational HOPE vehicle. "..Although the size and configuration of HOPE-X duplicate the operational HOPE, its gross weight will be about two-thirds of operational HOPE..." ${ }^{151}$ Three experimental projects were defined initially during the early development plans that would lead to HOPE-X as each project would focus on specific disciplinary development. A fourth vehicle was added to the initial three experimental projects during the later program stage. The HOPE-X program evolution and experimental projects timeline are shown in Figure 26, borrowed from Miyazawa, ${ }^{150}$

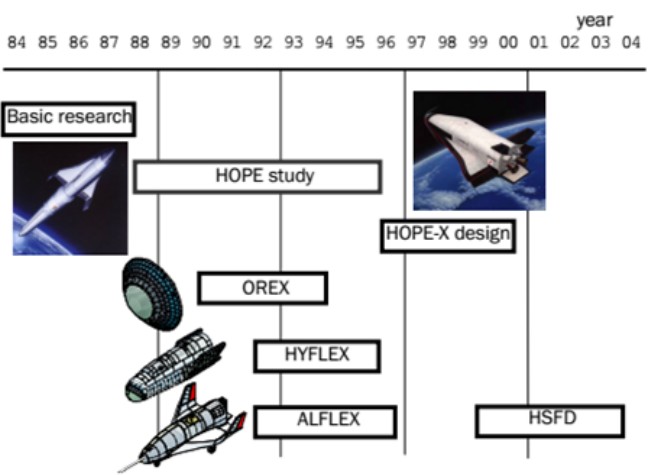

Figure 26: HOPE-X Program Timeline ${ }^{150}$ and are explained in the following discussion.

The OREX flight experiment, first in the series of HOPE-X precursors, was a blunt-cone shaped vehicle. After the early development phase, the OREX vehicle flew successfully in 1994 and provided important aerothermal data (wall temperatures and heat transfer rates) for the design of the TPS for HOPE. ${ }^{152}$

The OREX was followed by the Hypersonic Flight Experiment or HYFLEX, an unpowered lifting body that resembled the original HOPE-X configuration, unlike the conical OREX. The main objective of the HYFLEX was to explore guidance and control aspects of a lifting body and to utilize the aerothermal data from OREX by testing the TPS materials and structures. ${ }^{153}$ HYFLEX conducted a successful flight in 1996, testing the carbon-carbon heat shielding tiles that were intended to be used on HOPE, and provided data on hypersonic lifting, although the vehicle sank in the Pacific after splashdown before it could be recovered. ${ }^{154}$

ALFLEX, the last experimental project planned under HOPE-X was a one-third model of HOPE with a primary goal to develop an unmanned landing system for HOPE-X. "The ALFLEX flight tests were successfully conducted at Woomera in Australia in July and August of 1996 with the cooperation of Australian government. Approximately 20 flight tests were done to evaluate guidance performance, aerodynamic characteristics and performance." ${ }^{151}$ Both, HYFLEX and ALFLEX are scored high on the aerothermodynamics and subsystems disciplines for their contribution in stability and control during the landing, while OREX is scored high on the thermal management and aerothermodynamics disciplines.

In addition to the originally defined three experimental projects, the High-Speed Flight Demonstration (HSFD) program was added later in the HOPE-X program. The HSFD vehicle was a 25-percent scale test model of HOPE-X, defined with an objective to test technologies for the development of a future reusable launch vehicle. ${ }^{155}$ The HSFD program conducted successful test flights in two phases, "..Phase I to verify an approach and landing system for the return flight of a winged re-entry the vehicle that lands on a conventional runway, and Phase II to clarify the transonic aerodynamic characteristics of a winged reentry vehicle..." ${ }^{156}$ The HSFD flight test played an important role towards aerothermodynamics and sub-systems disciplines. The HSFD program is the last Japanbased case-study assessed in the AHP model and further infor-
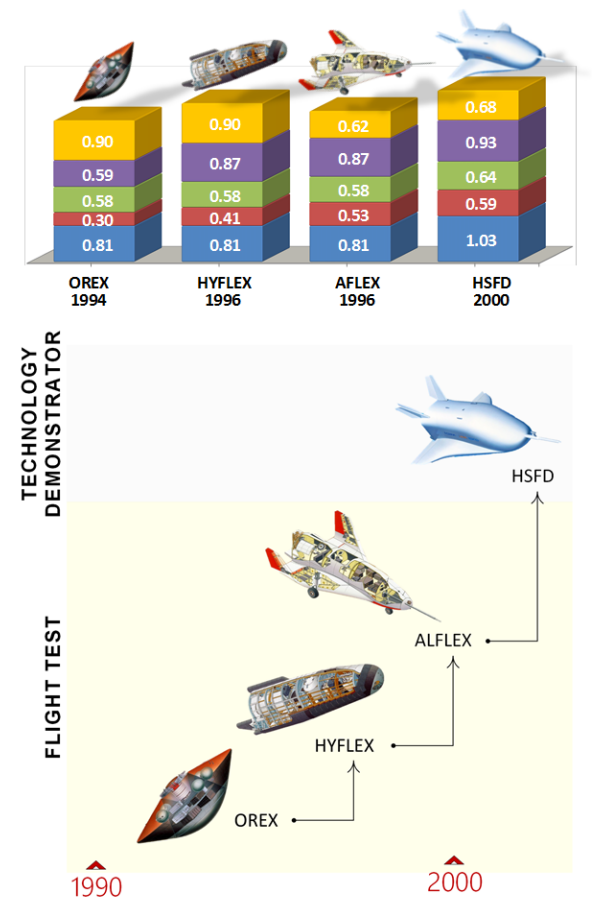

Figure 27: Japan LRV Efforts under HOPE Program mation about the vehicles and test flight results are found in reference [156].

Following the success of these experiments, HOPE-X design development continued from 1996 to 2000 during which the configuration changed from using wing-tip fins to twin canted fins on the aft fuselage. ${ }^{157}$ 
The HOPE-X vehicle was being developed to be launched using the new H-II launch vehicle. However, due to launch failure of the H-II vehicle in 1998 and 1999, ${ }^{158}$ the HOPE-X program was frozen in the middle of 2000 and eventually cancelled in 2003. ${ }^{150}$ HOPE-X is not included in the survey as the technology projects defined under the HOPE-X program provide more specific data and information than the unrealized HOPE-X.

The four case-studies from Japan are shown in Figure 27 with respective results from the AHP model.

\section{LRV Efforts in Soviet USSR}

The Soviet Union has been involved in the LRV design since as early as 1956 when Myasishchev began studies for a manned spaceplane. The primary objective was similar to the United States contemporary program $\mathrm{X}-20$; to execute piloted orbital military operations. This was followed by a series of small VKA designs eventually leading to an aerodynamically more efficient VKA-23 Design 2, after a major re-evaluation of the initial faceted wave riding configuration Design $1 .{ }^{16}$ Matthews elaborates further: "The second Myasishchev VKA-23 design was an elegant-looking, porpoise-fuselage winged vehicle, similar to Japan's HOPE design of forty years later. In comparison to the faceted first design, this version had a greater fuel load, much greater orbital maneuverability, and dispensed with the landing skis." ${ }^{159}$ The study reached detailed design stages with selection of specific components for vehicle structures \& materials, TPS and GNC disciplines. ${ }^{160}$ The design could not progress beyond ground test phase and was cancelled in 1960 leading to the OKBRocketplane, which further explored the VKA's program objectives. ${ }^{161}$

The OKB bureau overtook VKA 1960s objective to develop a manned military spaceplane to perform orbital reconnaissance and intercept American satellites. ${ }^{160}$ Several design concepts were studied including X-20 look alike delta-winged configurations, the most prominent one was the Racketoplan. The program conducted flight tests of aerodynamcally controlled vehicles, that came about two years before the USAF START program. This was the first ever hypersonic reentry test and provided important data that was utilized in various OKB designs. ${ }^{161}$ The Racketoplan was cancelled in 1965 as the Spiral became focus of LRV concepts. ${ }^{16}$ Further detailed information on the project is found in reference [17] and [162]

Spiral OS refers to the first generation of a design concept in a series of the Spiral 50-50 family ${ }^{163}$ which began in 1965 following the cancellation of Racketoplan. The OS orbiter concept was a lifting body configuration with flat bottom implmenting unique dihedral wings and was the baseline design which evolved in test vehicles, the Mig-105 and BOR family. The Sprial OS design was refined via wind-tunnel tests, while the program underwent several organizational changes in the early to mid 1970s. In 1975, the OS design was designated Experimental Piloted Orbital Aircraft(EPOS) and referred to an atmospheric flight test article, the Mig-105. ${ }^{16}$ The vehicle incorporated several design features and subsystems technologies from the OS design including a flat bottom lifting body configuration. Mig-105 conducted eight subsonic flights from 1976 to 1978 and were considered sufficient to characterize the spaceplane's subsonic aerodynamic characteristics and air-breathing propulsion systems. Another important LRV research project defined under the Spiralfamily was the BOR(unpiloted orbital rocketplane) family of test vehicles. BOR-1,-2 and -3 conducted suborbital flight tests from 1968-1969 for the Spiral program. When Spiral was cancelled in the wake of the Buran program, BOR-4 was already being developed to test heat shield materials, and was included in the Buran program. BOR-4 conducted four successful test flights where it confirmed the feasibility of the selected heat shield tile's materials and provided important data on the acoustic environment during launch and re-entry. BOR-4 was the last resulting vehicle from the Spiral program which generated critical data, technology and momentum that was utilized in the Buran vehicle. However it was resurrected in improved form in the 1980's as the MAKS spaceplane. ${ }^{16,17,163}$ The following quote by Siddiqi highlight the importance of the Spiral program:

"The Spiral project was huge, much larger than any of the previous spaceplane programs in the Soviet Union, certainly rivaling and perhaps exceeding the amount of effort the U.S. Air Force had invested in the Dyna-Soar program. The rich historical legacy of spaceplane research in the USSR, leading all the way back to the Sänger-Bredt studies in the late 1940s. served as a springboard for the new project." 17

The Soviet Shuttle program, Buran was established in 1976, in response to the definition of the US Space Shuttle in 1972 and is as well known as it's American counterpart. Buran represents the pinnacle of LRV effort in Soviet/Russian case-studies and developed and implemented state-of-art technology in most subsystems. Buran conducted only one unmanned orbital flight in its operational term and demonstrated a fully-automated landing. Buran's significance is highlighted by the following quote: 


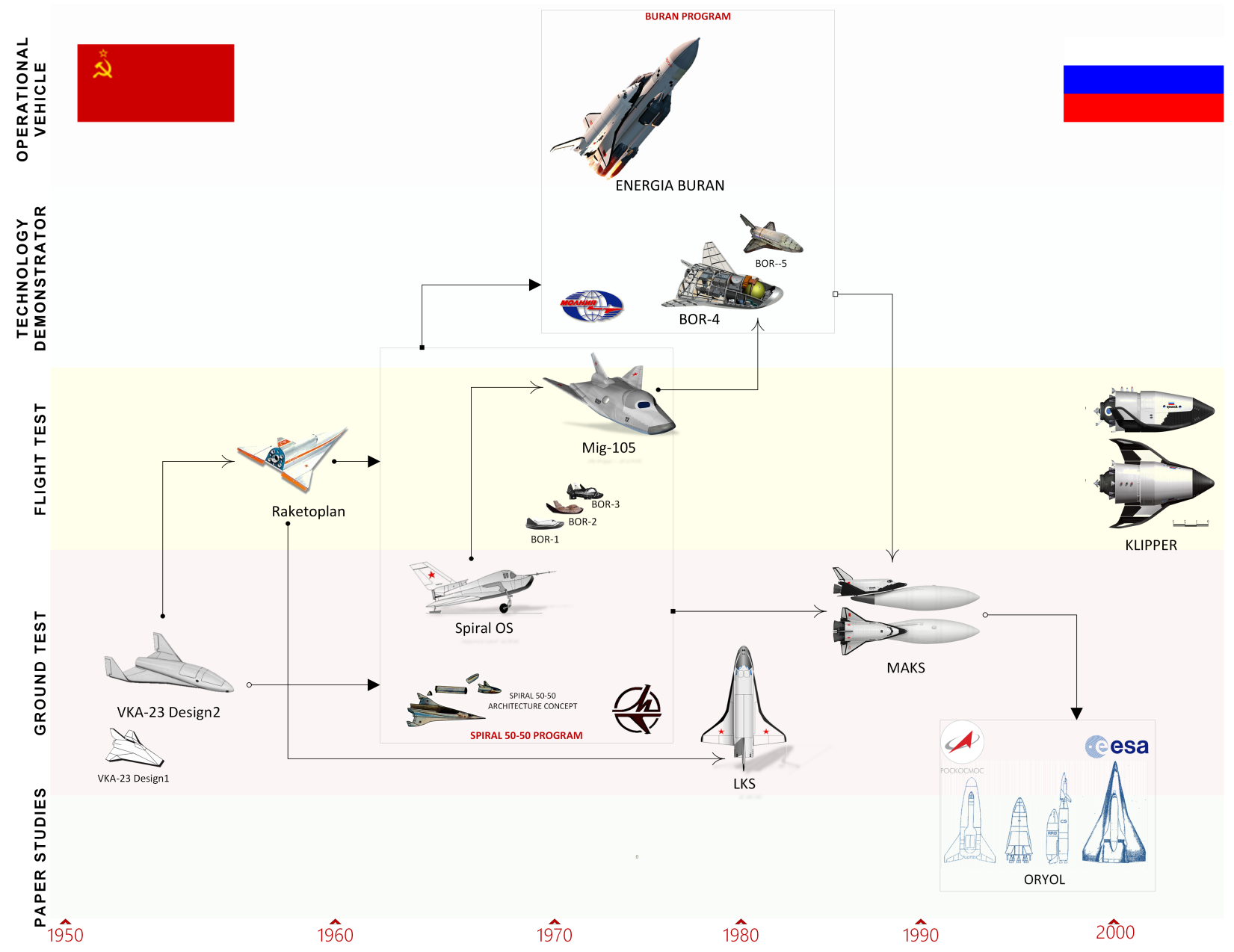

Figure 28: USSR/Russian LRV Programs Evolution

".. The development of Buran went on 10 years. Ten years during which important research tasks and experiments were carried out in various technical fields: acoustics, thermodynamics, systems design, dynamics of flight on simulator, design of the control panel, making of new materials, developing of methods and equipment for the landing in automatic mode (flying laboratories), atmospheric flight tests of the similar shuttle (another model of Buran with turbines, BTS-002), outsides tests of the heat shield and aerodynamic tests on BOR-4 and BOR-5 models, etc..." 164

'Energiya-Buran: The Soviet space shuttle'161 by Hendrix and Vis and the internet website in reference[164] are some of the most comprehensive account of the program and must be referred for further detailed information.

While the Buran program was in its peak during the late 1970s, Professor Chelomei from OKB-52 developed designs of a manned spaceplane based on his earlier cancelled Raketoplan program. The design was called the Light Space Plane (LKS) and plans for a prototype were completed by 1980. The LKS final design "..had a launch mass of 25 metric tons, including 4 to 5 metric tons of payload and 2 metric tons of maneuvering propellant. Maximum use was made of actual flight test data from the MP-1 and M-2 sub-scale Raketoplan vehicles flown in the early 1960's. Major spacecraft systems were off-the-shelf items developed for the Almaz / TKS space station (e.g. engine section, guidance elements, environmental control system, thermoregulation system, heat shield, reusable equipment)...In 1980 the 25 volume technical specification for the complete LKS system was completed, a full-size mock-up was built, and a 15 volume construction plan for a fleet of LKS orbiters was prepared." ${ }^{165}$ Although the program reached mock-up model stage showing a promising outlook in design feasibility, it was cancelled in 1983. 
MAKS was a scaled down version of Buran, that emerged out of studies from Project OK-M in the early 1980s. The highlight feature of the MAKS concept was it's capability to undertake a range of varied missions and could be launched vertically using a booster or air-launched atop a modified Antonov An-225. The air-launched proposal evolved into a more sophisticated design which was selected as the final MAKS configuration combining a reusable winged orbiter and expandable fuel tanks. This design concept closely resembled the ALSV program going on in the US around the same time. One of the main technical achievement from MAKS was the Glushko RD701 tri-propellant engine, specifically developed for the MAKS program. The propulsion system would initially use kerosene and LOX and then switch to liquid hydrogen and LOX to provide a higher specific impulse. For other sub-systems like the TPS material or the autnomous reentry, MAKS utilized the research base developed in the Buran program. The MAKS design reached mock-up model stage and most of the hardware for the demonstrator, MAKS-D was completed, ${ }^{166}$ when MAKS was cancelled in 1991 owing to national economic difficulties. ${ }^{16,167}$

The ORYOL program was initiated by the Russian Space Agency in 1993 as a research initiative to devise a stratergy for the development of the next generation of reusable space transportation systems. The study focussed on SSTO and TSTO orbital concepts based on a winged flyback and expandable second stage as air-launched systems were also considered through MAKS design. ${ }^{168,169}$ In terms of program objective and approach, ORYOL shared many similarities with the concurrent European FESTIP program, establishing an official cooperation between the RSA and the ESA in 1995. ${ }^{170}$ Both programs assessed similar system configuration concepts independently considered before the cooperation. These system concepts were compared and assessed against each other and "...led to a better understanding of both sides' approaches and requirements and to the recognition that the resp. technical views are rather compatible." 170 Figure 29 shows the concepts compared from ORYOL and FESTIP. The program was finished in 2001 with a general conclusion that best option to approach the next generation of space transportation system was to develop partially reusable TSTO system with flyback boosters and conventional rocket engines. ${ }^{161}$

The Kliper program was defined in 2004 as a replacement option for the Soyuz spacecraft. The initial concept proposed for the vehicle was a pure lifting body design that evolved to a lifting body with fold-able wings following several iterations to meet the requirements imple-

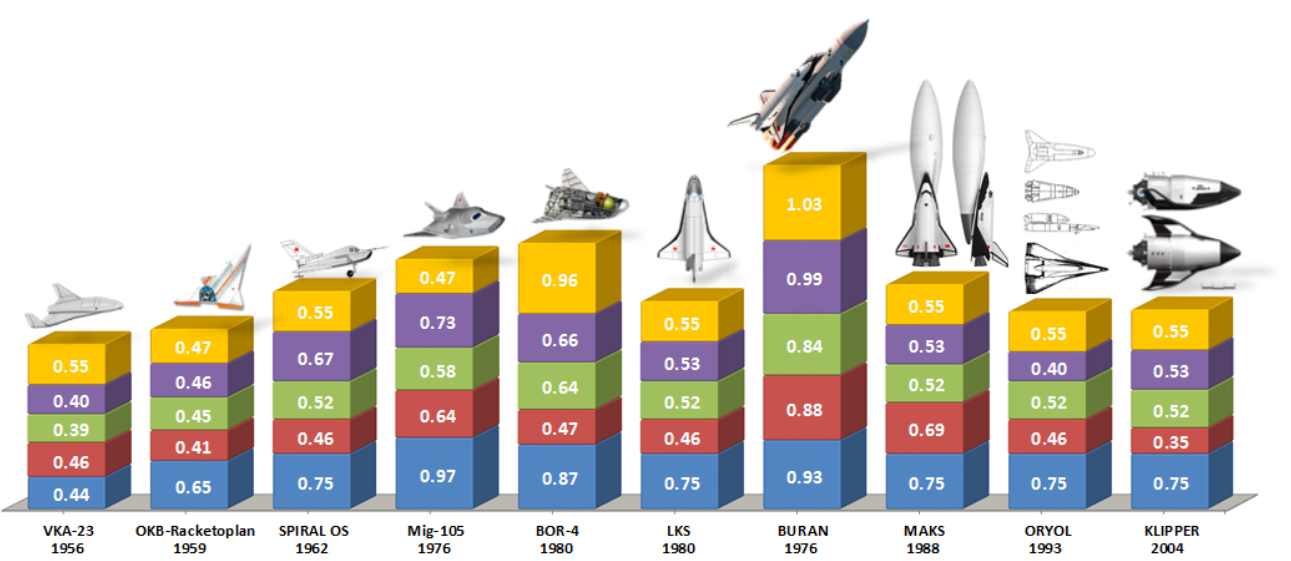

Figure 30: Soviet/Russian LRV Programs: AHP Evaluation mented by the upgraded Soyuz-2 rocket. Kliper had a unique configuration, unlike previous lifting bodies it was short and stout with a detachable habitation and service module mounted behind the glider. RSC Energia developed the design from 2006 onwards without Russian government's support and tried to seek private investment but failed to do so, as the program has been officially halted since 2007 with no signs of revival. ${ }^{164}$

The Kliper marks the end of the discussion for the USSR/Russian and the international LRV case-studies. The AHP evaluation of the Russian case-studies are shown in Figure 30 that compares the disciplinary and 
overall contribution.

\section{Conclusion}

The current paper provides a survey of major LRV programs, starting from Snger's Silvervogel in 1933 Germany, to the currently in development, SNC's DreamChaser. The survey is used as a basis for developing a quantified analytical framework, to assess the programs for their value and contribution towards the developments of primary hypersonic vehicle disciplines. The AHP-technique based model has analyzed sixty LRV case-studies and produced a comparative, numerical assessment of the programs. These results are further complemented by an overview of all the case-studies, highlighting the major accomplishments, and identifying important milestone efforts at disciplinary, and systems level. The study also serves as an extensive bibliography for major LRV programs throughout history, including more recent international research efforts.

Following goals were achieved through this survey:

1. Primary goal has been the development of an analytical framework and a working model developed using the AHP technique. The model is composed based on carefully formulated criteria to quantify, in essence, qualitative and non-tangible effects like the importance and contribution of historical programs towards design-discipline's growth and hypersonic-knowledge evolution.

2. An extensive literature review has been conducted, followed by a data-base build-up to define a structured classification of information. This process is used to effectively score the case-studies and identify common evolutionary trends among case-studies. The LRV evolutionary trends are charted for the programs developed in United States, Japan, Soviet/Russian and European space agencies.

3. The results are discussed in chronological order for each nation or group. The study provides an extensive bibliogrpahy for respective programs, and attempts to provide one of the most comprehensive historigraphy account of existing LRV programs to date, along with the analytical comparative assessment of the case-studies.

The case-studies are scored based on the data found to be available in the public-domain. Since not every program is documented in equal extensive details, the accuracy of the model can be further improved by including more data, and implementation by a more experienced user. The prototype, comparative framework can be expanded to capture more complicated effects like the amount of information available for each case-study. The model can also be used to evaluate other classes of the space access systems, given the evaluation criteria are defined suitably and specifically. This activity serves to identify the rich pockets of knowledge provided by the LRV history, which could be of special interests to companies like Sierra Nevada Corporation, who are developing the latest generation of LRV designs, and also for the current-day researcher, to enable them look farther by standing on the shoulders of these aerospace giants.

\section{Acknowledgments}

Authors wishes to express gratitude and appreciation towards works of historians and authors like; Haliion, Schweikart, Rose, Hirschel, Heppenheimer, Hoey, Draper, Miller, Erbland, Siddiqi, Geiger, Springer, and others. Their work in documenting the hypersonic history was a major influence and inspiration for this survey. The images used for graphical representation of the individual programs are collected from freely available images using Google, or recreated from one of the referenced sources. Author wishes to gratefully appreciate and acknowledge, Giuseppe De Chiara's graphics contribution from the presentation that he personally provided to the authors.

\section{References}

${ }^{1}$ Sanger-Bredt, I., "The Silver Bird story: a memoir," Essays on the History of Rocketry and Astronautics, Vol. 1, Vol. 1, 1977, pp. 195-228. 
${ }^{2}$ Ley, W., Rockets, Missiles, and Men in Space, Viking Press, 1968.

${ }^{3}$ Eggers Alfred, J., Julian, A. H., and Neice Stanford, E., "A Comparative Analysis of The Performance of Long-Range Hypervelocity Vehicles," NACA Research Memorandum, Washington: National advisory committee for Aeronautical, 1955.

${ }^{4}$ Godwin, R., Dyna-Soar: Hypersonic Strategic Weapons System, Vol. 35, Burlington, Ont.: Apogee Books, 2003.

${ }^{5}$ Barnhardt, M. and Candler, G. V., "Detached-eddy simulation of the reentry-F flight experiment," Journal of Spacecraft and Rockets, Vol. 49, No. 4, 2012, pp. 691-699.

${ }^{6}$ Erbland, P., "Current and near-term RLV/Hypersonic vehicle programs," RTO/AVT VKI Lecture Series on Critical Technologies for Hypersonic Vehicle Development, Brussels, Belgium, 2004, pp. 10-14.

${ }^{7}$ Hirschel, E., "Historical Perspective on Programs, Vehicles and Technology Issues," Critical Technologies for Hypersonic Vehicles Development, RTO-AVT-VKI Lecture Series, 2004.

${ }^{8}$ Hallion, R. P., "The history of hypersonics: or," Back to the future-again and again," 43rd AIAA Aerospace Sciences Meeting and Exhibit, 2005.

${ }^{9}$ Springer, A. M., "Historic Trends in RLV Design: Lessons Applicable to Future Concepts," 39th AIAA/ASME/SAE/ASEE Joint Propulsion Conference and Exhibit, 2003, p. 4589.

${ }^{10}$ Merriam-Webster, URL: http://www.merriam-webster.com/dictionary/historiography, [online accessed August, 2016].

${ }^{11}$ Bielat, R., "Transonic Aerodynamic Characteristics of the Dyna-soar Glider and Titan 3 Launch Vehicle Configuration with Various Fin Arrangements," Tech. rep., Langley Research Center, 1963.

${ }^{12}$ Hallion, R. and Schweikart, L., The hypersonic revolution:Vol 1 From Max Valier to Project PRIME (1924-1967), Vol. 3, Air Force History and Museums Program, 1998.

${ }^{13}$ Hallion, R. and Schweikart, L., The hypersonic revolution: Vol 2 From Scramjet to the National Aero-Space Plane (1964-1986), Vol. 3, Air Force History and Museums Program, 1998.

${ }^{14}$ Hallion, R. and Schweikart, L., The hypersonic revolution: Vol 3 The Quest for the Orbital Jet: The National AeroSpace Plane Program (1983-1995), Vol. 3, Air Force History and Museums Program, 1998.

${ }^{15}$ Bille, M., Williams, T., and Villhard, V., "Reusable Space Vehicles: Lessons From Four Decades of Futility," AIAA Paper, Vol. 659, 2003.

${ }^{16}$ Rose, B., Secret Projects: Military Space Technology, Midland Publishing, 2008.

${ }^{17}$ Siddiqi, A. A., Challenge to Apollo: the Soviet Union and the space race, 1945-1974, NASA, 2000.

${ }^{18}$ Siddiqi, A. A., The Soviet space race with Apollo, University Press of Florida, 2003.

${ }^{19}$ Bentley, M. A., Spaceplanes From Airport to Spaceport, Springer, 2009.

${ }^{20}$ Dick, S. J. and Launius, R. D., Critical issues in the history of spaceflight, Government Printing Office, 2006.

${ }^{21}$ Hannigan, R. J., Spaceflight in the Era of Aero-space Planes, Krieger Publishing Company, 1994.

${ }^{22}$ Launius, R. D. and Jenkins, D. R., Coming Home: Reentry and Recovery from Space, Government Printing Office, 2012.

${ }^{23}$ Heppenheimer, T. A., Facing the heat barrier: a history of hypersonics, National Aeronautics and Space Administration, NASA History Division, Office of External Relations, 2007.

${ }^{24}$ BRULLE, R. V., Engineering the Space Age, Air University Press, 2008.

${ }^{25}$ Ashford, D., Spaceflight revolution, Vol. 3, World Scientific, 2002.

${ }^{26}$ Hansen, J. R., "History of'space plane'concepts at Langley Aeronautical Laboratory 1952-1957," Journal of the British Interplenetary Society, 1987.

${ }^{27}$ Reubush, D., "A Historical Perspective on Hypersonic Research at the NACA/NASA Langley Research," AlAA Fourth International Aerospace Planes Conference, 1992.

${ }^{28}$ DRAPER, A. and SIERON, T., "Evolution and development of hypersonic configurations 19581990, Final report," ADA242768, 1991.

${ }^{29}$ Tolle, H., "Review of European aerospace transporter studies(European aerospace transporter, fundamental concepts and development)," Space Technology Conference, Palo Alto, CA, 1967, pp. 120-128.

${ }^{30}$ Wuest, W., "Review of German work on controlled re-entry technology," Progress in Aerospace Sciences, Vol. 20, No. 4, 1983, pp. 217-318.

${ }^{31}$ Becker, J. V., "The Development of Winged Reentry Vehicles 1952-1963," from Richard T. Layman Personal Files, NASA., 1983.

${ }^{32}$ Hoey, R. G., Testing Lifting Bodies at Edwards, Citeseer, 1994.

${ }^{33}$ Reed, R. D. and Lister, D., Wingless flight: the lifting body story, University Press of Kentucky, 1997.

${ }^{34}$ Becker, H. J., NASA: Space Flight Research and Pioneering Developments, Schiffer Publishing, February $28,2012$.

${ }^{35}$ Heribert Kuczera, P. W. S., Reusable Space Transportation Systems, Springer-Verlag GmbH, 2011.

${ }^{36}$ Bertin, J. J. and Cummings, R. M., "Fifty years of hypersonics: where we've been, where we're going," Progress in Aerospace Sciences, Vol. 39, No. 6, 2003, pp. 511-536.

${ }^{37}$ Bertin, J. J. and Cummings, R. M., "Critical Hypersonic Aerothermodynamic Phenomena," Annu. Rev. Fluid Mech., Vol. 38, 2006, pp. 129-157.

${ }^{38}$ Muylaert, J. and Berry, W., "Aerothermodynamics For Space Vehicles: Esa'S Activities And The Challenges," ESA bulletin, , No. 96, 1998, pp. 22-32.

${ }^{39}$ Thornton, E. A., "Thermal structures-four decades of progress," Journal of Aircraft, Vol. 29, No. 3, 1992, pp. $485-498$.

${ }^{40}$ Kempel, R. W., Kirsten, P., and Strutz, L., "Stability and control derivatives of the lifting body vehicles," 1970.

${ }^{41}$ NASA, "NASA History Program Office Website," 2016.

${ }^{42}$ Hirschel, E. H., Basics of aerothermodynamics, Springer, 2005.

${ }^{43}$ Galman, B. A., "Some fundamental considerations for lifting vehicles in return from satellite orbit," Planetary and Space Science, Vol. 4, 1961, pp. 399-410. 
${ }^{44}$ Love, E. and Pritchard, E., "A look at manned entry at circular to hyperbolic velocities," AIAA Second Manned Space Flight Meeting, Dallas, Texas, 1963.

${ }^{45}$ Dissel, A. F., Kothari, A. P., and Lewis, M. J., "Comparison of horizontally and vertically launched airbreathing and rocket vehicles," Journal of spacecraft and rockets, Vol. 43, No. 1, 2006, pp. 161-169.

${ }^{46}$ Berry, W. and Grallert, H., "Performance and technical feasibility comparison of reusable launch systems: A synthesis of the ESA winged launcher studies," Acta astronautica, Vol. 38, No. 4, 1996, pp. 333-347.

${ }^{47}$ Jenkins, D. R., Space Shuttle: The History of the National Space Transportation System: The First 100 Missions, Specialty Pr Pub \& Wholesalers, 2001.

${ }^{48}$ Satty, T. L., The analytic hierarchy process, New York: McGraw-Hill New York, 1980.

${ }^{49}$ Hirschel, E. and Kuczera, H., "The FESTIP Technology Development And Verification Plan," 1998.

${ }^{50}$ Osborne, L., Brummond, J., Hart, R. D., Zarean, M., and Conger, S. M., "Clarus: Concept of operations," Tech. rep., 2005.

${ }^{51}$ Jacobsen, A., Operation Paperclip : the secret intelligence program to bring Nazi scientists to America., New York: Little, Brown and Company., ISBN 0316221058.

52 AviationWeek, "US Aviation Week 2008 Person of the Year: Qian Xuesen," Aviation Week and Space Technology, 2008.

${ }^{53}$ Krafft Ehricke, M. F., Krafft Ehricke's Extraterrestrial Imperative, Collector's Guide Publishing, 2009.

${ }^{54}$ EHRICKE, K. A., "MX-2276 Advanced Strategic Weapon System. Preliminary Global System Study," Tech. rep., DTIC Document, 1955.

${ }^{55}$ Postle, R., Decreval, R., Isenberg, J., Cheng, H., Gill, W., Hanawalt, A., Landphair, L., McKowen, P., Pallone, A., and Roehrs, F., "MX-2276 Advance Strategic Weapon System. Aerodynamics," Tech. rep., DTIC Document, 1955.

${ }^{56}$ Agency, A. S. T. I., "BRASS Bell Reconnaisance Aircraft Weapon System," Tech. rep., DTIC Document, 1957.

${ }^{57}$ Geiger, C. J., "Strangled Infant: The Boeing X-20A Dyna-Soar," Hallion, ed., Hypersonic Revolution, Vol. 1, 1998, pp. $185-377$.

${ }^{58}$ Geiger, C. J., "Termination of the X-20A Dyna-Soar," History of Aeronautical Systems, 1964.

${ }^{59}$ Geiger, C. J., "History of the X-20A Dyna-Soar. Volume I." Tech. rep., DTIC Document, 1963.

${ }^{60}$ Houchin, I. et al., The Rise and Fall of Dyna-Soar: A History of Air Force Hypersonic R63D, 1944-1963., Ph.D. thesis, Auburn University, Auburn Alabama, 1995.

${ }^{61}$ Heppenheimer, T. A., The space shuttle decision: NASA's search for a reusable space vehicle, Vol. 4221, JSTOR, 1999.

${ }^{62}$ Bono, P. and Gatland, K., "Frontiers of space." Frontiers of space., by Bono, P.; Gatland, K.. New York, NY (USA): Macmillan, 248 p., Vol. 1, 1969.

${ }^{63}$ Fuller, R. ., "ASTRO Concept," Astronautics 8 Aeronautics, 1964.

${ }^{64}$ Fellenz, D. W., "Reusable aerospace passenger transport - Study of incremental development approaches Summary report," Tech. rep., 1967.

${ }^{65}$ Akridge, C. M. and Fellenz, D. W., "Design considerations for orbital transport systems," Tech. rep., 1967.

${ }^{66}$ Kempel, R. W., Painter, W. D., and Thompson, M. O., "Developing and flight testing the HL-10 lifting body: A precursor to the Space Shuttle," 1994.

${ }^{67}$ McDonnell, "McDonnell ASSET : Fact Sheet," Tech. rep., McDonnell Aircraft Corporation, 1964.

${ }^{68}$ NASA, "Space Shuttle Summary Report, Revision 1," Tech. rep., NASA, 1969.

${ }^{69}$ Dore, "Aircraft Design and Development Experience Related to Reusable Launch Vehicles," AAS, AAS Science \& Technology, 1969.

${ }^{70}$ Martellucci, A., "Maneuvering Aerothermal Technology (MAT) Program. Data Bibliography." Tech. rep., Science Applications Inc., Wayne, PA, 1981.

${ }^{71}$ Astronautica, E., "Boost-Glide Re-entry Vehicle," URL : http://www.astronautix.com/b/boostglider-entryvehicle.html [online access August, 2016], 2016.

${ }^{72}$ Most, M., "FINAL REPORT for Re-entry "F" Nose Vibration and Shock Test," Tech. rep., NASA, 1967.

${ }^{73}$ Wood, W. A., Riley, C. J., and Cheatwood, F. M., "Reentry-F Flowfield Solutions at 80,000 ft." 1997.

${ }^{74}$ Air Force, F. D. L., "Air Force Systems Command, Technology Program Plan: NHFRF," Tech. rep., Wright-Patterson AFB, OH, Jan. 1977.

${ }^{75}$ Logsdon, J. M., "Space-Shuttle Decision-Technology And Political Choice," Journal of Contemporary Business, Vol. 7 , No. 3, 1978, pp. 13-30.

${ }^{76}$ Pace, S., Engineering design and political choice: the space shuttle 1969-1972, Ph.D. thesis, Massachusetts Institute of Technology, 1982.

${ }^{77}$ Lulla, K., "An Overview of contributions of NASA Space Shuttle to Space Science and Engineering education," 39th COSPAR Scientific Assembly, Vol. 39 of COSPAR Meeting, July 2012, p. 1124.

${ }^{78}$ Hepler, A. K. and Bangsund, E., "Technology requirements for advanced earth orbital transportation systems. Volume 2: Summary report," Tech. rep., NASA, 1978.

${ }^{79}$ Day, D., "Fire in the sky: the Air Launched Sortie Vehicle of the early 1980s," 2016.

${ }^{80}$ Schneider, S. P., "Flight data for boundary-layer transition at hypersonic and supersonic speeds," Journal of Spacecraft and Rockets, Vol. 36, No. 1, 1999, pp. 8-20.

${ }^{81}$ Johnson, L. and Mora, C., Sandia National Laboratories: A History of Exceptional Service in the National Interest, Sandia National Laboratories, 1997.

${ }^{82}$ Kuperman, G. G., "Information Requirements Analyses for Transatmospheric Vehicles," Tech. rep., DTIC Document, 1992.

${ }^{83}$ Gonzalez, D., Eisman, M., Shipbaugh, C., Bonds, T., and Tuan Le, A., "Proceedings of the RAND Project AIR FORCE Workshop on Transatmospheric Vehicles," Tech. rep., DTIC Document, 1997.

36 of 40 
${ }^{84}$ Talay, T. A., "The HL-20 Personnel Launch System," AIAA Space Programs and Technologies Conference, Huntsville, $A L, 1992$, pp. 24-27.

${ }^{85}$ EHRLICH, C. F., "HL-20 concept-Design rationale and approach," Journal of Spacecraft and Rockets, Vol. 30, No. 5, 1993, pp. 573-581.

${ }^{86}$ Center, N. L. R., "HL-20 Model for Personnel Launch System Research: A Lifting-Body Concept," URL: https://www.nasa.gov/centers/langley/news/factsheets/HL-20.html [online access August, 2016], June 2011.

${ }^{87}$ Chiara, G. D., "From HL-20 to Dream Chaser," 2012.

${ }^{88}$ Global, R., "Rocketplane Global, Inc." URL: http://www.rocketplane.com/ [online access August, 2016].

${ }^{89}$ Zubrin, R. and Clapp, M. B., "Black Horse: One Stop to Orbit," 1995.

${ }^{90}$ FAA, "Reusable Launch Vehicle Programs And Concepts," 1998.

${ }^{91}$ Freeman, D. C., Talay, T. A., and Austin, R. E., "Reusable launch vehicle technology program," Acta Astronautica, Vol. 41, No. 11, 1997, pp. 777-790.

${ }^{92}$ Sumrall, J., Lane, C., and Cusic, R., "VentureStar tm reaping the benefits of the X-33 program," Acta astronautica, Vol. 44, No. 7, 1999, pp. 727-736.

${ }^{93} \mathrm{GAO}$, "Status of the X-33 Reusable Launch Vehicle Program," 1999.

${ }^{94}$ Barton, G. H. and Tragesser, S. G., "Autolanding trajectory design for the X-34," AIAA Paper, , No. 99-4161, 1999.

${ }^{95}$ Sullivan, R. B. and Winters, B., "X-34 program overview," Proceedings of the 34th AIAA/ASME/SAE/ASEE Joint Propulsion Conference and Exhibit, AIAA Paper, Vol. 98, 1998, p. 3516.

${ }^{96}$ Sygulla, D., Klädtke, R., Püttmann, N., and Graft, E., "X-38, CRV and CRV Evolution Program Overview and European Role," Acta Astronautica, Vol. 48, No. 5, 2001, pp. 859-868.

${ }^{97}$ Aerospazio, A., "International cooperation on X-38 and crew return vehicles (X-38/CRV) for the International Space Station," 1998

${ }^{98}$ Labbe, S. G., Perez, L. F., Fitzgerald, S., Longo, J. M., Molina, R., and Rapuc, M., "X-38 integrated aero-and aerothermodynamic activities," Aerospace science and technology, Vol. 3, No. 8, 1999, pp. 485-493.

${ }^{99}$ NASA, "NASA Armstrong Fact Sheet: X-38 Prototype Crew Return Vehicle," 2014

${ }^{100}$ Paez, C. A., "The development of the X-37 re-entry vehicle," AIAA Paper, Vol. 4186, 2004, pp. 2004.

${ }^{101}$ Grantz, A. C., "X-37B orbital test vehicle and derivatives," AIAA SPACE 2011 Conference E3 Expositio, n AIAA-2011$7315,2011$.

${ }^{102}$ Taylor, F. W. and Howard, R., "Dream Chaser TM for Space Transportation: Tourism, NASA and Military Integrated on a Atlas V," 2008.

${ }^{103}$ McAlister, P., "CCiCap Announcement Summary Portfolio," Commercial Spaceflight NASA Headquarters.

${ }^{104}$ NASA, "NASA Awards International Space Station Cargo Transport Contracts," URL: https://www.nasa.gov/pressrelease/nasa-awards-international-space-station-cargo-transport-contracts/ [online access August, 2016], Jan. 142016.

${ }^{105}$ SNC, "Sierra Nevada Corporation Successfully Completes Dream Chaser Study with German Aerospace Industry Partners," URL: http://www.sncorp.com/AboutUs/NewsDetails/749 [online access August, 2016].

${ }^{106}$ Meyer-Allyn, M., Metts, J., Anderson, D., Johnson, J., and Quinn, G., "Dream Chaser Thermal Control System: An Overview," 42nd International Conference on Environmental Systems, 2012, p. 3452.

${ }^{107}$ Meyer-Allyn, M., Metts, J., Anderson, D., Johnson, J., and Heldmann, M., "Dream Chaser Environmental Control and Life Support System: An Overview," 42nd International Conference on Environmental Systems, 2012, p. 3453.

${ }^{108}$ Zea, L., Over, S., Klaus, D., Tanner, J., and Stroud, K., "Development of a Cockpit Architecture for the Dream Chaser Orbital Vehicle," 42nd International Conference on Environmental Systems, 2012, p. 3421.

${ }^{109}$ Story, G., Zoladz, T., Arves, J., Kearney, D., Abel, T., and Park, O., "Hybrid propulsion demonstration program 250 K hybrid motor," Proc. 39th AIAA/ASME/ASEE JPCE, Huntsville, AI, 2003, pp. 23-28.

${ }^{110}$ Sänger, E. and Bredt, J., A rocket drive for long range bombers, Cornog, 1944.

${ }^{111}$ Sanger, E. and Bredt, J., "A Rocket Drive For Long Range Bombers," Tech. rep., Deutsche Luftfahrtforschung, 1944.

${ }^{112}$ Sanger, E., Rocket Flight Engineering, National Aeronautics and Space Administration, 1965.

${ }^{113}$ Sanger, H. E. and Szames, A. D., "From the Silverbird to Interstellar Voyages," 54th International Astronautical Congress of the International Astronautical Federation, the International Academy of Astronautics, and the International Institute of Space Law, 2003, pp. IAA-2.

${ }^{114}$ Flightglobal, "Bumerang," FLIGHT Global International Magazine, 23 March 1972.

${ }^{115}$ Heyman, J., "Cancelled Projects: ERNO Bumerang," Trios Space Information News Bulletin Vol. $38,2012$.

${ }^{116}$ Hoffmann, H., "The space laboratory: A European-American cooperative effort," Tech. rep., NASA, 1981.

${ }^{117}$ Herholz, J., "European Space Transportation System Projects since 1998," The 9th International Mars Society Conference, Washington DC, 3-6 Aug 2006.

${ }^{118}$ Sacher, P., "The Engineering Design of Engine/Airframe Integration for the SÄNGER Fully Reusable Space Transportation System," Tech. rep., DTIC Document, 2010.

${ }^{119}$ GAO, "AEROSPACE PLANE TECHNOLOGY Research an Development Efforts in Europe," July 1991.

${ }^{120}$ Ransom, S. and Hoffmann, D.-I. R., "PLATO - A European Platform Orbiter Concept," Science ES Technology, 1990, pp. 9.

${ }^{121}$ Ransom, S., Hoffmann, R., and Unternehmensgruppe Raumfahrt, Messerschmitt-Bölkow-Blohm GmbH (MBB), O., PLATO: a European platform orbiter concept ; AeroTech 89, National Exhibition Centre, Birmingham, 31.10.-3.11.1989, MBB UO PUB, Zentrale Berichtsstelle, Technisch-wissenschaftliche Information, Messerschmitt-Bölkow-Blohm, 1989.

${ }^{122}$ David, W. G., "Space vehicle radiators," Oct. 27 1970, US Patent 3,536,278.

${ }^{123}$ Gerald, D., Philip, S., and Thomas, W., "Space vehicles," Feb. 20 1968, US Patent 3,369,771.

${ }^{124}$ FLIGHT, "Economic Space Transport," FLIGHT International, March, 1966. 
${ }^{125}$ Krige, J., Russo, A., and Sebesta, L., A history of the European Space Agency 1958-1987, JSTOR, 2000.

${ }^{126}$ Cretenet, J., "Hermes vehicle," Acta Astronautica, Vol. 12, No. 11, 1985, pp. 949-958.

${ }^{127}$ Bayer, M., "Hermes: Learning from our mistakes," Space Policy, Vol. 11, No. 3, 1995, pp. 171-180.

${ }^{128}$ Perrier, P., "Major lessons learned in hypersonic design of Hermes," Aerothermodynamics for space vehicles, Vol. 367, 1995, p. 603.

${ }^{129}$ Chaumette, D. and Cretenet, J.-C., "Hermes thermal protection system overview," Acta Astronautica, Vol. 16, 1987, pp. 391-399.

${ }^{130}$ Jouhaud, F., "Closed loop reentry guidance law of a space plane: Application to Hermes," Acta Astronautica, Vol. 26, No. 8 , 1992, pp. 577-585.

${ }^{131}$ Kuczera H, J. C., "The Major Results of the FESTIP System Study," 9th International Space Planes and Hypersonic Systems and Technologies Conference, Norfolk, VA, USA, 1 - 5 November 1999.

${ }^{132}$ Kuczera, H., Sacher, P., and Dujarric, C., "FESTIP system study-An overview," AIAA 7th International Space Planes and Hypersonic Systems and Technologies Conference, Norfolk, Virginia, 1996.

${ }^{133}$ Immich, H. and Caporicci, M., "Status of the FESTIP rocket propulsion technology programme," AIAA paper, 1997, pp. 97-3311.

${ }^{134}$ Immich, H. and Caporicci, M., "FESTIP technology developments in liquid rocket propulsion for reusable launch vehicles," AIAA Paper, , No. 1996-3113, 1996.

${ }^{135}$ Dujarric, C., Caporicci, M., Kuczera, H., and Sacher, P., "Conceptual studies and technology requirements for a new generation of European launchers: Paper IAF-97-V. 3.03a FESTIP status report," Acta astronautica, Vol. 41, No. 4, 1997, pp. 219-228.

${ }^{136}$ Bayer, M., "Description of the FESTIP VTHL-TSTO System Concept Studies," unpublished study report URL: http://thehuwaldtfamily. org/jtrl/research/Space/Launch/Vehicles/FESTIP-FESTIP-Two Stage To Orbit Launch Vehicle, Bayer. pdf.

${ }^{137}$ Sacher, P. W., "European experimental test vehicle options," Air 6 Space Europe, Vol. 3, No. 1, 2001, pp. 85 - 91.

${ }^{138}$ Ackermann, J., Breteau, J., Kauffmann, J., Ramusat, G., and Tumino, G., "The road to the Next-Generation European Launcher - an overview of the FLPP," ESA Bulletin, Vol. 123, Aug. 2005, pp. 6-12.

${ }^{139}$ Grard, Y., "FLPP Re-entry In-Flight Experimentation: current status of the Intermediate eXperimental Vehicle (IXV)," 57th International Astronautical Congress, International Astronautical Congress (IAF), 2006.

${ }^{140}$ Barrio, A. M. and Sudars, M., "EXPERT-The ESA experimental Re-Entry Test-bed. Trajectory and mission design." AIAA Guidance, Navigation, and Control Conference, Portland, OR, USA, 2011.

${ }^{141}$ Ratti, F. and Gavira, J., "EXPERT-The ESA experimental re-entry test-bed: System overview," AIAA, Vol. 7224, 2009, pp. 2009.

${ }^{142}$ Baiocco, P., "Pre-X experimental re-entry lifting body: design of flight test experiments for critical aerothermal phenomena," Tech. rep., DTIC Document, 2007.

${ }^{143}$ Chavagnac, C., Moulin, J., and Guedron, S., "The Hypersonic Pre-X Vehicle: Current Status," Space TechnologyAbingdon, Vol. 23, No. 2-3, 2003, pp. 153-164.

${ }^{144}$ Baiocco, P., Guedron, S., Plotard, P., and Moulin, J., "The Pre-X atmospheric re-entry experimental lifting body: Program status and system synthesis," Acta Astronautica, Vol. 61, No. 1, 2007, pp. 459-474.

${ }^{145}$ Russo, G., De Matteis, P., Sabatano, R., Richiello, C., and Marino, G., "USV: Unmanned Space Vehicle," Memorie della Societa Astronomica Italiana, Vol. 79, 2008, pp. 863.

${ }^{146}$ Russo, G., "USV Status 2011: New Steps Ahead," 17th AIAA International Space Planes and Hypersonics and Technologies Conference, San Francisco, USA, Vol. 11, 2011, p. 14.

${ }^{147}$ Tumino, G. and Gerard, Y., "IXV: the Intermediate eXperimental Vehicle-Europe among the world players in atmospheric reentry," ESA bulletin, Vol. 128, 2006, pp. 62-67.

${ }^{148}$ Ratti, F., Gavira, J., Thirkettle, A. C., Thoemel, J., and Ritter, H., "Instrumentation on board the European Experimental Re-entry test bed EXPERT," ESA-ESTEC, 2010.

${ }^{149}$ SPACE.com, "European Mini-Space Shuttle Aces 1st Test Flight," URL: http://www.space.com/28520-europe-launchesmini-shuttle-ixv.html [online access August, 2016].

${ }^{150}$ Miyazawa, Y., "Current Status of Japanese Aerospace Programs-Focusing on the High Speed Flight Demonstration," Automatic Control in Aerospace 2004, 2005, pp. 25.

${ }^{151}$ Maita, M. and Kobayashi, S., "Japanese Spaceplane and Hypersonic Technology Program overview-Progress of 19951996," Space Plane and Hypersonic Systems and Technology Conference, 1996, p. 6005.

${ }^{152}$ Weiland, C., Aerodynamic Data of Space Vehicles, Springer Science \& Business Media, 2014.

${ }^{153}$ Shirouzu, M. and Yamamoto, M., "Overview of the HYFLEX Project," AIAA, International Space Planes and Hypersonic Systems and Technologies Conference, 7 th, Norfolk, VA, 1996.

${ }^{154}$ Inouye, Y., Fujii, K., Takizawa, M., Takaki, R., Watanabe, S., and Ito, T., "Flight results of HYFLEX onboard measurements," AIAA, International Space Planes and Hypersonic Systems and Technologies Conference, 7 th, Norfolk, VA, 1996.

${ }^{155}$ Shirouzu, M., Ishimoto, S., Miyazawa, Y., and Yanagihara, M., "Development of hope-x and high speed flight experiment," NAL Research Progress 1998, Vol. 2000, 2001, pp. 8-11.

${ }^{156}$ Yanagihara, M. and Munenaga, T., "High speed flight demonstration project," Proc. 24th Annu. Allerton Conf. Circuits and Systems Theory Congress of International Council of the Aeronautical Sciences, 2004, pp. 2004-7.

${ }^{157}$ Ishimoto, S., Shirouzu, M., Kochiyama, J., and Fukui, T., "Modification of HOPE-X aerodynamic configuration," International Symposium on Space Technology and Science, 22 nd, Morioka, Japan, 2000, pp. 1109-1113.

${ }^{158}$ JAXA, "'H-II Launch Vehicle". Launch Vehicles and Space Transportation Systems." JAXA Website URL: http://global.jaxa.jp/projects/rockets/h2/index.html [online access August, 2016]. 
${ }^{159}$ Matthews, H., The Secret Story of the Soviet Space Shuttle, publisher not identified, 1994.

${ }^{160}$ Pesavento, P., "Russian Space Shuttle Projects, 1957-1994, Part 3," Spaceflight, Vol. 37, No. 7, 1995, pp. $226-229$.

${ }^{161}$ Hendrickx, B. and Vis, B., Energiya-Buran: the Soviet space shuttle, Springer Science \& Business Media, 2007.

162 Astronautica, E., "Raketoplan," URL: http://www.astronautix.com/r/raketoplan.html, [online access August, 2016].

${ }^{163}$ Astronautica, E., "Spiral OS," URL: http://www.astronautix.com/s/spiralos.html, [online access August, 2016].

${ }^{164}$ Website, "Buran - Reusable soviet space shuttle." URL: http://www.buran-energia.com/bourane-buran/bouranedesc.php [online access August, 2016]. 2016].

${ }^{165}$ Astronautica, E., "LKS-Chelomei spaceplane," URL: http://www.astronautix.com/l/lks.html, [online access August,

${ }^{166}$ Skorodelov, V., “"Experimental aerospace system MAKS-D”," G. Lozino-Lozinskiy, A. Bratukhin, op. cit, 1996, pp. 308-311.

${ }^{167}$ Hempsell, M. and Parkinson, B., "MAKS - Eastern Promise ?" SPACEFLIGHT, Vol. 35, March 1993.

${ }^{168}$ Lanshin, A. and Sosounov, V., "Russian Aerospace Combined Propulsion Systems Research and Development Program (" ORYOL-2-1"): Progress Review," Space Plane and Hypersonic Systems and Technology Conference, 1996, p. 4494.

${ }^{169}$ Kostromin, S., Romashkin, A., and Efanova, G., "Study On Validation Of Design Principles Of The ORYOL Space Transportation System," 1996.

${ }^{170}$ Anfimov, N., Kostromin, S. F., Kuczera, H., Sacher, P. W., and Bayer, M., "ORYOL-FESTIP Cooperation: Comparison of Concepts and First Conclusions," 8th International Space Planes and Hypersonic Systems and Technology Conference, Paper No. AIAA, 1998, pp. 89-1544.

\section{Appendix}

\section{A. Legend for Figures}

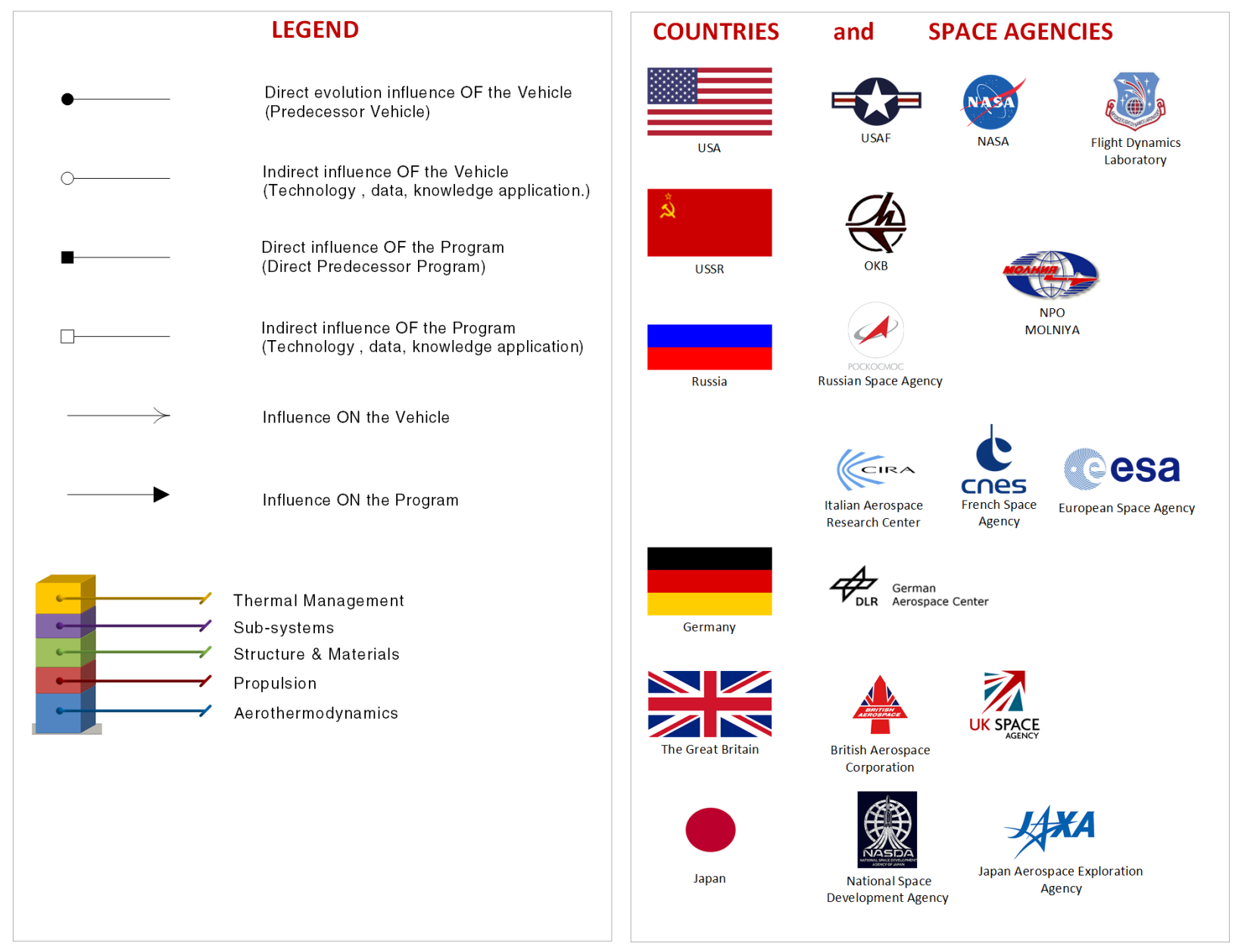

Figure 31: Legend used in LRV Evolution and AHP Results plots 
B. Abbreviations

Table 4: Abbreviations List

\begin{tabular}{|c|c|}
\hline Abbreviations & Full-forms \\
\hline \multicolumn{2}{|c|}{ Vehicles/Programs } \\
\hline AFLEX & Automatic Landing Experiment \\
\hline ALSV & Air Launched Sortie Vehicle \\
\hline ASSET & Aerothermodynamic Elastic Structural Systems Environmental Tests \\
\hline BGRV & Boost Glide Re-entry Vehicle \\
\hline BOMI & Bomber-Missile \\
\hline CRV & Crew Return Vehicle \\
\hline EXPERT & Experimental Re-entry Testbed \\
\hline FESTIP & Future European Space Transportation \\
\hline HORUS & Hypersonic Orbital Upper Stage \\
\hline HSFD & High Speed Flight Demonstration \\
\hline HYFLEX & Hypersonic Flight Experiment \\
\hline HYWARDS & Hypersonic Weapon And R\& D System \\
\hline ILRV & Integrated Launch and Re-entry Vehicle \\
\hline IXV & Intermediate eXperimental Vehicle \\
\hline MAKS & Mnogotselevaya aviatsionno-kosmucheskaya sistema \\
\hline MUSTARD & Multi-Unit Space Transport And Recovery Device \\
\hline OREX & Orbital Re-entry Experiment \\
\hline PILOT & Piloted Low-speed Test \\
\hline PLATO & Platform Orbiter \\
\hline PRIME & Precision Recovery Including Maneuvering Entry \\
\hline RASV & Reusable Aerodynamic Space Vehicle \\
\hline ROBO & Rocket Bomber \\
\hline RTTOCV & Reusable Ten-Ton Orbital Carrier Vehicle. \\
\hline START & Spacecraft Technology and Advanced Reentry Tests \\
\hline STS & Space Transportation System \\
\hline SWERVE & Sandia Winged Energetic Reentry Vehicle Experiment \\
\hline TAV & Trans Atmospheric Vehicles \\
\hline USV & Unmanned Space Vehicle \\
\hline \multicolumn{2}{|l|}{ Organizations } \\
\hline $\mathrm{BAC}$ & British Aircraft Corporation \\
\hline CIRA & Italian Aerospace Research Center \\
\hline CNES & Centre national d'tudes spatiales \\
\hline DLR & German space agency \\
\hline EADS LV & European Aeronautic Defence and Space Company \\
\hline ESA & European Space Agency. \\
\hline FDL & Flight Dynamics Laboratory \\
\hline JAXA & Japan Aerospace Exploration Agency \\
\hline MBB-ERNO & Messerschmitt-Boelkow-Blohm/ERNO Raumfahrttechnik \\
\hline NASDA & National Space Development Agency of Japan \\
\hline OKB & Tupolev Design Bureau \\
\hline RSA & Russian Space Agency \\
\hline SNC & Sierra Nevada Corporation' \\
\hline VKA & Military Space Force, USSR \\
\hline \multicolumn{2}{|l|}{ General Terms } \\
\hline $\mathrm{CAV}$ & Cruise Acceleration Vehicle \\
\hline LRV & Lifting Reentry Vehicle \\
\hline SAS & Space Access System \\
\hline SSTO & Single Stage to Orbit \\
\hline TSTO & Two Stage to Orbit \\
\hline VTHL & Vertical Takeoff Horizontal Landing \\
\hline
\end{tabular}

40 of 40 